\title{
Hacia una definición del estilo Ychsma: aportes preliminares sobre la cerámica Ychsma tardía de la pirámide III de Pachacamac
}

Vers une définition du style Ychsma: apports préliminaires de la céramique Ychsma Récent de la Pyramide III de Pachacamac

Towards a definition of the ychsma style: a preliminary contribution on Late ychsma ceramics from piramid iii at pachacamac

Jane Feltham y Peter Eeckhout

\section{(2) OpenEdition}

Journals

Edición electrónica

URL: http://journals.openedition.org/bifea/5157

DOI: 10.4000/bifea.5157

ISSN: 2076-5827

\section{Editor}

Institut Français d'Études Andines

\section{Edición impresa}

Fecha de publicación: 1 diciembre 2004

Paginación: 643-679

ISSN: 0303-7495

\section{Referencia electrónica}

Jane Feltham y Peter Eeckhout, « Hacia una definición del estilo Ychsma: aportes preliminares sobre la cerámica Ychsma tardía de la pirámide III de Pachacamac », Bulletin de I'Institut français d'études andines [En línea], 33 (3) | 2004, Publicado el 08 diciembre 2004, consultado el 02 diciembre 2020. URL : http://journals.openedition.org/bifea/5157 ; DOI : https://doi.org/10.4000/bifea.5157

Les contenus du Bulletin de l'Institut français d'études andines sont mis à disposition selon les termes de la licence Creative Commons Attribution - Pas d'Utilisation Commerciale - Pas de Modification 4.0 International. 


\title{
HACIA UNA DEFINICIÓN DEL ESTILO YCHSMA: APORTES PRELIMINARES SOBRE LA CERÁMICA YCHSMA TARDÍA DE LA PIRÁMIDE III DE PACHACAMAC
}

\author{
Jane FELTHAM *, Peter EECKHOUT **
}

\begin{abstract}
Resumen
Este artículo trata del estilo Ychsma en cuanto se refiere al Ychsma Tardío. Las excavaciones en la pirámide III y el Templo del Mono han dado a luz un buen corpus de material cerámico, tanto de vasijas enteras como de tiestos diagnósticos. Los fechados radiocarbónicos colocan el Ychsma Tardío desde fines del siglo catorce hasta la llegada de los incas en la Costa Central. Hay dos fases del estilo. La primera precede la llegada de los incas y la segunda evolucionó durante el Incanato, ya que ellos introdujeron nuevas formas y técnicas decorativas. Las técnicas de fabricación junto con la evolución de las formas y la decoración son debidamente documentadas. Por último se propone un nuevo método de seriación, la cual confirma la colocación de ciertas formas y técnicas decorativas dentro de estas fases.
\end{abstract}

Palabras claves: Cerámica, Pachacamac, estilo Ychsma o Ychsma Tardío.

\section{VERS UNE DÉFINITION DU STYLE YCHSMA : APPORTS PRÉLIMINAIRES DE LA CÉRAMIQUE YCHSMA RÉCENT DE LA PYRAMIDE III DE PACHACAMAC}

\section{Résumé}

Cet article traite de l'évolution du style Ychsma et plus spécifiquement du style Ychsma Récent. Les fouilles de la pyramide III et du Temple du Singe ont mis à jour un bon corpus de matériel céramique, aussi bien de vases entiers que de tessons diagnostiques. Les datations absolues situent l'Ychsma Récent à partir de la fin du quatorzième siècle jusqu'à l'arrivée des Incas sur la côte centrale. Le style comprend deux phases : la première précède l'arrivée des Incas et la seconde s'est développée sous l'Empire inca, avec l'introduction de nouvelles formes et techniques décoratives. Les techniques de fabrication ainsi que l'évolution des formes et de la décoration sont dûment détaillées. Enfin, une nouvelle méthode de sériation est proposée, laquelle confirme la position chronologique de certaines formes et techniques décoratives au sein de ces phases.

Mots clés : Céramique, Pachacamac, style Ychsma ou Ychsma Récent.

\footnotetext{
*Unversity of Liverpool, Reino Unido. E-mail: suzemil@liverpool.ac.uk

*** Université Libre de Bruxelles, Bélgica. E-mail: peeckhou@ulb.ac.be
} 


\title{
TOWARDS A DEFINITION OF THE YCHSMA STYLE: A PRELIMINARY CONTRIBUTION ON LATE YCHSMA CERAMICS FROM PIRAMID III AT PACHACAMAC
}

\begin{abstract}
This article discusses the evolution of the late Ychsma style. Recent excavations in pyramid complex no III have uncovered a fine corpus of ceramic material which includes complete vessels as well as diagnostic sherds. Radiocarbon dates place the Late Ychsma style from the end of the 14th century to the arrival of the Incas on the central coast. There appear to be two phases in the style, the first of which precedes the Inca regime. The second phase refers to the period under the Incas who introduced new forms and decorative techniques. Manufacturing techniques as well as the evolution of forms and their decoration are given full discussion. Finally a new method of seriation is proposed, which confirms the placement of certain forms and decorative features within these phases.
\end{abstract}

Key words: Ceramics, Pachacamac, Ychsma style or late Ychsma.

Dentro del marco del proyecto Ychsma, uno de los temas que despierta mayor interés es el de la cerámica. Por lo tanto creemos importante difundir los resultados de nuestras primeras temporadas en cuanto a la cerámica Ychsma se refiere. Enfocaremos este artículo sobre la alfarería encontrada en el complejo piramidal $n^{\circ}$ III (1) durante las investigaciones realizadas allí entre enero y marzo de 1999 y en setiembre-octubre de 2000. Dichas excavaciones se concentraron en las partes altas del complejo, es decir en las plataformas A y B y en los ambientes asociados, y en el Templo del Mono y su plaza asociada, que es la Plaza IV (Fig. 1). En 1999 la superficie total de las excavaciones alcanzó $458 \mathrm{~m}$ Cada ambiente o recinto fue explorado sistemáticamente con el propósito de recoger evidencias sobre el carácter de la ocupación. En varias ocasiones las excavaciones llegaron hasta la roca madre porque queríamos obtener columnas estratigráficas que se podrían relacionar con el desarrollo del edificio a la vez que deseábamos saber más de las ocupaciones anteriores a la construcción del complejo. Una serie de 24 muestras radiocarbónicas han sido fechadas (Michczynski et al., 2003), lo cual nos ha permitido definir una cronología muy detallada, tanto de la historia del edificio como del material asociado. Volveremos más tarde a estos puntos cronológicos.

En efecto en 1999 hubo 469 bolsas de tiestos procedentes de dichas excavaciones con un total de más de 60000 tiestos. Unos 3000 de estos, es decir un $5 \%$, se consideraban diagnósticos. Entre estos había varios estilos, algunos de los cuales se remontaban hasta el Intermedio Temprano. Los siguientes estilos fueron reconocidos: el Inca Provincial, el Inca-Chimú, el Ychsma, el Lima, el Nievería y un estilo llano del Intermedio Temprano. Los tiestos de los estilos tempranos siempre son pequeños y algo deteriorados en los bordes, lo que nos lleva a pensar que provienen del relleno de los pisos y de los adobes de los muros. No se encuentran en un contexto seguro debajo de

(1) El complejo piramidal III está compuesto de dos pirámides, A y B, y de un edificio algo apartado de estas que llamamos el Templo del Mono. 


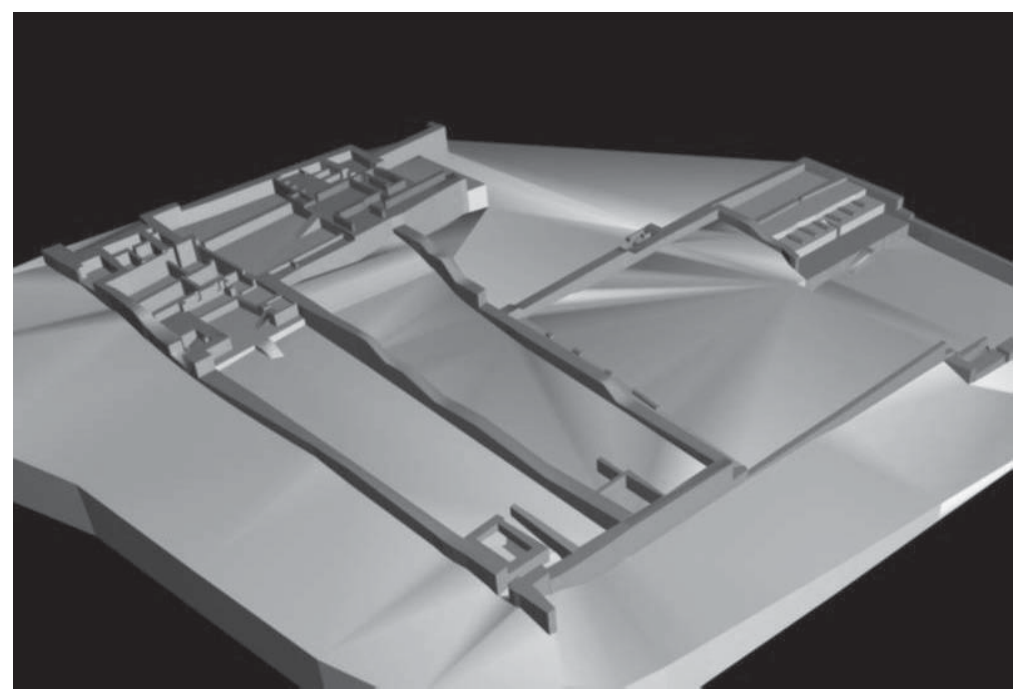

Fig. 1 - Reconstitución del complejo piramidal III de Pachacamac que muestra las dos pirámides, la IIIA y la IIIB junto con el Templo del Mono.

las ocupaciones tardías, pues se encuentran tanto en la superficie como en las capas inferiores. No vamos a detenernos en estos estilos tempranos, ni en el estilo de Cuzco, lo cual pensamos hacer en una presentación futura. Por ahora nos interesa considerar el estilo Ychsma y los problemas que han surgido en cuanto a su definición, problemas que todos los que trabajan con este material han hecho resaltar.

Todos reconocemos la importancia histórica del sitio de Pachacamac en el desarrollo de la arqueología científica del Perú. Los trabajos pioneros de Max Uhle a fines del siglo XIX le permitieron establecer la primera secuencia relativa de cerámica procedente de tumbas en la América del Sur, un logro que a partir de ese entonces ha servido de base para las secuencias elaboradas en los Andes Centrales hasta hoy día (Uhle, 1903). Sin embargo, a pesar de la importancia del trabajo de Uhle, hay que reconocer que nuestros conocimientos respecto a la alfarería tardía de Pachacamac todavía permanecen limitados. Las razones de esto son las siguientes:

Uno: la huaquería que viene afectando el sitio desde la Conquista. Uhle (1903: 12) calculó que había entre 60000 y 80000 tumbas en Pachacamac pero hasta la fecha actual solo una docena han sido debidamente excavadas y documentadas.

Dos: el hecho de que la mayor parte de la cerámica encontrada consiste en cerámica llana de poco valor estético en comparación con otros estilos del Intermedio Tardío, como por ejemplo, el Chimú, el Chancay y el Ica, de modo que no les ha llamado la atención a muchos investigadores.

Tres: la falta de fechados absolutos hasta hace poco. Los treinta y dos fechados obtenidos dentro del marco del proyecto Ychsma (Michczynski et al., 2003; Eeckhout, 1999: 380-381) representan un $90 \%$ del total de los fechados disponibles para el sitio de Pachacamac. Dichos fechados serán 
complementados dentro de poco con otros 25 que están siendo procesados en este momento, y con otros que saldrán de las excavaciones en curso.

Cuatro: La profusión de nomenclaturas respecto a la cerámica tardía de los valles del río Rímac y del río Lurín. Cada investigador ha empleado un término diferente para esta cerámica pasando del Huancho del Padre Villar Córdova (1935) y Francisco Iriarte (1960), por el Sub-Chancay de Gordon Willey (1943), Late Red, Black and White o Inca Associated de Strong \& Corbett (1943) hasta el Orangeware (Feltham, 1983; 1984), Lurin Orange (Eeckhout, 1999) y el Ichimay/ Ichma de otros investigadores recientes (Bueno, 1978; 1982; Bazán del Campo, 1990; 1992; Franco Jordán, 1998; Díaz \& Vallejo, 2002). Al mismo tiempo muchos han señalado una variedad de pastas y decoraciones y solo en la última década se han empezado los intentos de sintesizar todas las informaciones.

Según vemos, uno de los problemas que han surgido alrededor de las definiciones se debe al hecho de que muchos han trabajado con tiestos y no los han relacionado con una vasija entera o casi entera que conocen. Hay que subrayar que los antiguos no fabricaban tiestos, sino vasijas. Por esto se debe cuidar en no crear tipos únicamente a base de tiestos porque esto crea una profusión tipológica que no ayuda en nada a comprender la evolución del estilo. Damos, como ejemplo, el caso de un pequeño tiesto con lo que parece ser un engobe blanco y una decoración en negro. Entonces se crea una clase o tipo "negro sobre blanco", cuando en efecto el tiesto proviene de un cuenco que tiene un engobe rojo, sobre el cual hay una capa de pintura blanca y luego la decoración en negro, pero solo los dos últimos rasgos aparecen en el tiesto. Sin embargo esto no se toma en cuenta y el tiesto llega a ser clasificado en una categoría poco válida (2).

Otro problema es el de la clasificación de colores. En efecto para el estilo entero no hay más que tres: un negro, un rojo y un blanco que hacen contraste el uno con el otro. Sin embargo muchos investigadores, queriendo ser muy precisos, hablan de otros colores, como el marrón y el amarillo. En realidad el negro a veces toma un matiz marrón y el blanco parece amarillento, pero son los contrastes entre los colores lo que importan y no todos los matices que pueda haber; en realidad estos matices resultan de ligeras diferencias durante el proceso de cocción. Esto no quiere decir que los matices diferentes que se notan no tengan ninguna importancia para designar a alfareros, localidades, diferencias temporales etc., pero que en el estado actual de nuestros conocimientos sería algo aventurado examinar esto sin estar seguros de la secuencia de formas y cambios de decoración a través del tiempo, la cual todavía ignoramos.

(2) Hay que poner énfasis en este punto porque muchos han hablado de un tipo "negro sobre blanco" (Paredes \& Ramos, 1994: 346; Bazán, 1990: 169; Eeckhout, 1999: 46-47) a base de tiestos, lo que implica un engobe total blanco con decoración en negro como se ve en el estilo Chancay Tardío. Si uno repasa las colecciones de cerámica de fines del Horizonte Medio/principios del Intermedio Tardío como las de Huallamarca, o de Bandelier en Pachacamac, se da cuenta que las vasijas con una decoración de negro sobre blanco llevan diseños negros sobre paneles o bandas blancas sobre un fondo que tiene el color natural de la pasta (que suele ser naranja o marrón claro) o sobre un engobe rojo. Entonces no se trata de un estilo "negro sobre blanco" como el de Chancay. Tampoco se trata del Tricolor Geométrico cuyo centro de difusión parece ser la costa nor-central, si bien tiene semejanzas. Además las vasijas nuestras tienen una superficie mate y no bruñida como la del Tricolor Geométrico (vease la nota 4 ). 
Antes de proseguir conviene dar una definición del territorio de los Ychsmas pasando desde luego al estilo. A través de sus estudios etnohistóricos María Rostworowski ha dado a entender que el señorío de Ychsma abarcaba los valles bajos del Lurín y del Rímac, extendiéndose hasta Manchay en el Lurín y Pariachi en el Rímac (1972; 1978: 59). No hay motivo para dudar de esta definición. Sin embargo se ha notado que la cerámica que vamos a tratar aquí se encuentra más allá del mismo territorio de los Ychsmas, porque se ha encontrado en la orilla sur del Chillón e incluso en Chilca. En el Lurín se encuentra hasta 500 m.s.n.m. en Huaycán y Molle. Más allá de esos sitios, donde empieza la Chaupi Yunga, no es tan frecuente y parece que solo en el Horizonte Tardío encontramos fragmentos en la zona de Sisicaya (3). A lo mejor esto se debe a la conquista Inca que dio lugar a los desplazamientos de poblaciones y a viajes frecuentes a otros lugares por parte de los campesinos que hacían su mit'a. También hay que recordar que los incas establecieron una provincia de Pachacamac, cuyas fronteras no coincidían con las de los Ychsmas, pues parece que aquellos incluyeron a los Collique del valle bajo del Chillón en esta nueva provincia (Cornejo, 1999: 8; 2000: 149).

Si bien fue María Rostworowski (1972; 1977; 1978: 50) la primera en señalar la importancia del nombre Ychsma para designar a los antiguos habitantes de los valles del Rímac y Lurín, los trabajos arqueológicos del doctor Arturo Jiménez Borja y de Alberto Bueno $(1978 ;$ 1982) establecieron el uso de este nombre Ichimay/Ichma para la cultura de dichos valles. Más tarde Francisco Bazán del Campo hizo la primera síntesis de la cerámica $(1990 ; 1992)$, rechazando por completo el nombre de Huancho propuesto por Villar Córdova (1935) e Iriarte Brenner (1960), y dando el nombre correcto de Ychsma al estilo de cerámica prevalente en la región después del Horizonte Medio. En los años recientes otros aportes han sido publicados por Paredes Botoni \& Ramos Giraldo (1989), Franco Jordán (1998) y por Díaz \& Vallejo (2002). Los cuadros cronológicos de estos autores están reproducidos en cada estudio y serán comentados a continuación.

En su estudio del valle de Pachacamac (1982) Alberto Bueno da unas breves noticias del estilo Ychsma haciendo hincapie en las formas "cara-gollete". El cuadro cronológico al final del estudio coloca el estilo Ychsma dentro de las Formaciones Señoriales, es decir entre 1200 y 1470 d. C., pero no subdivide el estilo entre temprano, medio y tardío, si bien el énfasis sobre los tipos de cara-gollete hace pensar que está describiendo un Ychsma Tardío. Por otra parte Bazán del Campo hace esta subdivisión en su resumen del estilo que llama Ychsma. Él presenta un cuadro con la secuencia de los estilos en los tres valles de la Costa Central, aunque no da fechados absolutos para sus períodos (Bazán del Campo, 1992: cuadro 1). Sostiene que el Ychsma Inicial empieza en la tercera época del Horizonte Medio y continúa hasta la cuarta A, época en

(3) Cuando la primera autora trabajaba en el valle medio del Lurín en los años 70 del siglo pasado encontró bastantes fragmentos del estilo Ychsma alrededor de Molle, Huaycán y algunos en Chontay (ver Feltham, 1983; 1984), pero en ese entonces lo llamó orangeware por el tipo de pasta que contrastaba con la del valle arriba que era marrón. Además apenas se había difundido el nombre de Ychsma. Al repasar sus apuntes está claro que la mayor parte de los fragmentos eran del Ychsma Tardío tal como se define aquí. Más allá de Chontay hay poquísimos fragmentos de lo que se llama Ychsma Medio, aunque estos se encuentran en Panquilma, Huaycán y Molle, lo cual parece confirmar la separación de la zona de Sisicaya de la de Huaycán en el Intermedio Tardío. 
que el Ychsma Medio lo reemplaza. El Ychsma Medio continúa hasta fines del Intermedio Tardío para ser reemplazado por el Ychsma Tardío en el Horizonte Tardío. La categoría Ychsma Fitomorfo existe como entidad separada durante todos los periodos de desarrollo del estilo Ychsma. Coetáneo con el Ychsma Inicial y la primera aparición del Ychsma Medio va el Tricolor Geométrico (4). La descripción del estilo Ychsma está más concentrada en el Ychsma Inicial y Medio y no proporciona muchos datos escritos sobre el estilo Ychsma Tardío, aunque casi todas las láminas, desde la 8 hasta la 47, contienen dibujos de vasijas y tiestos denominados Ychsma Tardío, procedente la mayor parte de Armatambo. Volveremos a estos dibujos como punto de comparación con lo nuestro.

Los cuadros cronológicos de Franco Jordán (1998: 70 y 71) son los únicos que proponen fechas, quizá porque disponía de fechados radiocarbónicos. Considera que el estilo Ychsma está arraigado en el Intermedio Tardío, es decir después de 1050 d.C., aunque no lo divide en Ychsma Inicial/Medio/Tardío, como lo hace Bazán del Campo. Por lo contrario, divide el estilo del Intermedio Tardío en tres fases según los tipos característicos de cada fase.

- La fase uno incluye tipos Inciso-Punzonado, es decir con decoración punteado en zona, tipos con y sin pintura, y un tipo amarillo pálido sobre el color natural de la pasta cocida;

- la fase dos incluye tipos con engobe rojizo bruñido y sin bruñir, tricolor blanco negro y rojo y un tipo bruñido;

- la fase tres incluye un tipo marrón obscuro/amarillo pálido.

Para el Horizonte Tardío hay muchos tipos: un tipo Inca Asociado, un tipo amarillo pálido/engobe rojo, o blanco sobre rojo, un tipo llano sin pintura; un negro bruñido o pulido y un Inca Imperial. Sin embargo no está claro si los primeros de estos tipos del Horizonte Tardío son el resultado de una evolución del estilo Ychsma o no. Aunque su descripción de la evolución de los tipos es bastante correcta, discrepamos de él en algunos puntos, por ejemplo, hay una pequeña proporción de negro bruñido en el Intermedio Tardío y el tipo llano sin pintura existe desde los comienzos del estilo Ychsma. Al mirar el cuadro parece que su tricolor blanco, negro y rojo de la fase dos no persiste en la fase tres ni en el Horizonte Tardío, lo que no es probable porque en realidad es el tipo Inca Asociado o sea el Ychsma Tardío.

Para el sitio de Las Palmas, que es un sector de Pachacamac, Paredes \& Ramos (1989) presentan una descripción minuciosa de varios tipos de la cerámica Ychsma si bien no la llaman así (5). Colocan la cerámica recuperada en el Intermedio Tardío y el Horizonte Tardío. Hacen resaltar el hecho de que los tipos del Intermedio Tardío siguieron siendo producidos durante el Incanato (Paredes \& Ramos, 1989: 347). Por

(4) A veces es difícil saber lo que quieren decir varios autores por el término Tricolor Geométrico. Parece que a veces hablan del estilo comentado por Strong (1925) y Menzel (1977), el cual es un conjunto de algunos rasgos Wari con formas locales (a veces con cuatro colores y no tres); otras veces es evidente que se refieren al estilo Ychsma Tardío, o Inca Asociado, que también tiene muchos elementos geométricos en tres colores, pero este suele ser mate mientras que el verdadero Tricolor Geométrico tiene un ligero bruñido, según se ve en los ejemplares de Ancón y Pachacamac.

(5) Ellos hacen referencia (1989: 344) a un cuadro cronológico 5, pero desgraciadamente falta. 
ejemplo proponen que la cerámica llana y sencilla perdura durante todo el Intermedio Tardío hasta el Horizonte Tardío con poca variación de formas y que el tipo Negro sobre Blanco tiene sus raíces en la primera parte del Intermedio Tardío junto con el tipo Engobe Rojo y que siguió siendo producido en el Horizonte Tardío (Paredes \& Ramos, 1989: 346). Aunque Díaz \& Vallejo clasifican la cerámica de Las Palmas en Ychsma Medio (2002: figura 9, cuadro cronológico), algunos tiestos demuestran elementos del Ychsma Tardío, por ejemplo el tipo Negro sobre Blanco o Crema (6), que en realidad proviene de los cuencos carenados (o aquillados) con decoración en blanco y negro sobre un engobe rojo (fig. 40 a-c). Otros elementos del Ychsma Tardío son los cuencos carenados del tipo negro pulido (fig. $43 \mathrm{f}$ ) y asas que unen el labio con la parte superior del cuerpo (fig. 34). Por otra parte los investigadores de Las Palmas no han encontrado muchas evidencias de la cerámica de los incas, pues no hay más que un aríbalo y muy poca cerámica del tipo negro pulido: unos 28 tiestos entre 3175 (Paredes \& Ramos, 1989: cuadro 3). Faltan también otros elementos indicativos de la cerámica Ychsma de los incas, como por ejemplo las serpientes modeladas en el cuerpo o el cuello de las vasijas. Pero a pesar de esto es probable que Paredes y Ramos tengan toda la razón al decir que el sector estuvo ocupado durante dichas épocas. Como prueba, hacen mención del tipo de vasija con pestaña en pasta marrón tosco (p. 347 y fig. 45a).

A fines del siglo pasado Eeckhout resumió nuestros conocimientos del estilo (1999: 33-75) pero como Paredes y Ramos trató tipos en vez del estilo entero y no lo llamó Ychsma. Para la zona del valle bajo del Lurín que incluye Pachacamac, repartió la cerámica en 4 tipos generales: Lurín Orange y Engobe Rouge (los cuales pertenecen al estilo Ychsma), Brun Lissé (la cerámica del valle alto) y Noir Poli (Negro Pulido que forma una pequeña parte del estilo Ychsma). Dentro de estos tipos hubo 14 pastas y 7 formas, las cuales difieren un poco de las descritas aquí. Con la ayuda de las excavaciones estratigráficas de Pachacamac ha podido crear una seriación de las formas entre estos cuatro tipos. Sin embargo una ojeada a los cuadros donde presenta los resultados de la seriación (Eeckhout, 1999: 72-74) demuestra que la mayor parte de los fragmentos estudiados son del siglo quince. Los fechados radiocarbónicos le ayudan a dar fechas absolutas a las formas y tipos de decoración si bien no los subdivide en un Ychsma Inicial, Medio y Tardío. En efecto las seriaciones propuestas confirman muchas de nuestras hipótesis sobre el Ychsma Tardío y ayudan a clarificar algunos puntos.

En resumen se puede decir que hay algún acuerdo sobre lo que constituye el Ychsma Tardío, sobre todo por cuanto toca al tipo negro y blanco sobre rojo pero faltan muchos detalles, como por ejemplo una discusión seria del tipo de decoración denominado punteado en zona. Un intento serio de separar el Ychsma Medio del Ychsma Tardío ha sido el estudio reciente de Díaz y Vallejo sobre contextos Ichma en Armatambo (Diaz \& Vallejo, 2002). Ellos han podido aislar la cerámica del Ychsma Medio por medio de sus excavaciones en un basural y en tumbas que no muestran evidencias de cerámica

(6) En un párrafo anterior hemos comentado los problemas con este tipo que no parece proceder de una vasija con engobe blanco y motivos pintados de negro al estilo del Chancay Tardío, sino de vasijas con paneles o bandas blancas sobre el color natural de la pasta o sobre un engobe rojo (véase figura 11). 
Inca ni la que suele estar asociada con esta. En el Ychsma Medio la poca decoración queda limitada a brochazos blancos formando bandas alrededor del cuello a la que agregan unas líneas negras en contadas veces. Llama la atención la falta general de un engobe rojo como base para la pintura blanca. Las formas son sencillas: jarras con cuello evertido, recto, abombado o compuesto, con algunos frascos y tinajas. Díaz y Vallejo han realizado un estudio de mucho valor, subrayando la diferencia entre los contextos descritos para Armatambo que son del Ychsma Medio y los contextos de otros sitios recopilados en su cuadro cronológico, que son del Ychsma Tardío. Para ellos las características del Ychsma Tardío consisten en vasijas con morfología Inca, vasijas con aplicaciones decorativas hechas en molde, culebras, sapos, vasijas con contorno aquillado con una decoración de negro sobre blanco, y ollas con asas cintadas uniendo el labio con la parte superior del cuerpo (Díaz \& Vallejo, 2002: 70) (7). Por lo dicho es evidente que una porción de la cerámica de Las Palmas es del Ychsma Tardío lo que confirma las propuestas de Paredes y Ramos. En efecto en su cuadro cronológico Díaz y Vallejo identifican el Ychsma Tardío con el Inca (Díaz \& Vallejo, 2002: figura 9, cuadro cronológico), colocando el Ychsma Medio y Temprano en el Intermedio Tardío, si bien no niegan la existencia de un Ychsma Tardío antes del Incanato. Aquí está el punto difícil que produce muchos debates: ¿el Ychsma Tardío es fruto de la conquista Inca y el aumento de contactos con otras regiones o es algo que iba evolucionando lentamente antes de la conquista Inca? o sea ¿es anterior o no a la conquista Inca? Esperamos que lo expuesto abajo ayude a resolver este problema.

Pasando a una descripción en términos generales vamos a definir el estilo Ychsma como un estilo de dos componentes: uno llano y otro decorado, el cual fue fabricado en la Costa Central a partir de fines del Horizonte Medio hasta fines del Horizonte Tardío, e incluso en los principios de la época colonial. Las técnicas de fabricación se ven en el cuadro adjunto:

\section{Cuadro 1 - Técnicas de fabricación.}

1. Con rollos: cuerpo, cuello y a veces las bases

2. Modelado: bases, asas, y a veces pequeñas vasijas en miniatura

3. Moldeado: figurinas y vasijas Chimú-Inca e Inca-Ychsma del Horizonte Tardío

4. Combinación de todas estas técnicas

El método más común de fabricar una vasija era formar el cuerpo y el cuello por medio de rollos de arcilla. A veces modelaban la base sobre un fragmento de una vasija rota. Muchas veces se notan los vestigios de los rollos en el interior de una vasija cuando

(7) Después de escribir este artículo, salió a fines de 2004 otro artículo de Díaz y Vallejo que contribuye mucho a nuestros conocimientos del Ychsma Tardío por su analisis de material procedente de otros sitios del Rímac. Ellos subdividen el estilo en dos fases: A antes del Incanato y B durante el Incanato (Ver bibliografía). 
no la han alisado bien. Según vemos, los moldes no se empleaban hasta el Horizonte Tardío y entonces solo para figurinas y algunas vasijas negras del estilo Inca-Chimú o Inca-Ychsma y algunas aplicaciones (Fig. 2). Solían modelar algunos apéndices zoomorfos que se encuentran en las vasijas de todas las etapas de la evolución del estilo (Fig. 3).

a)

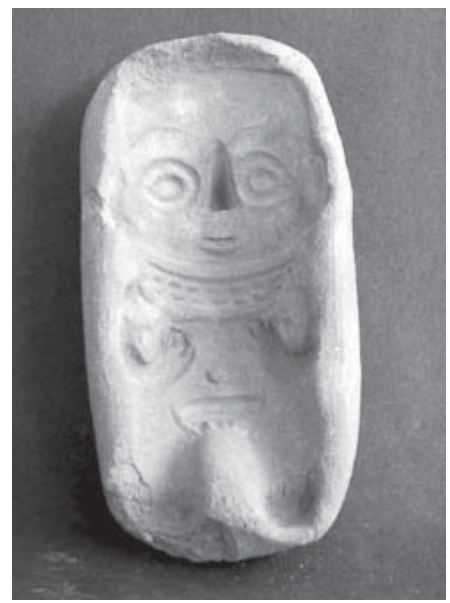

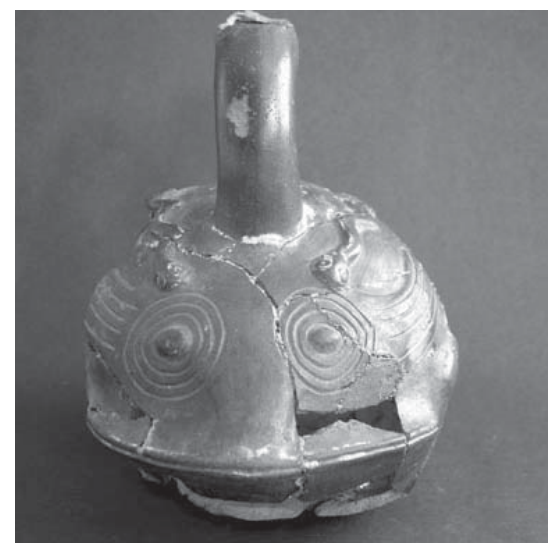

b)

Fig. 2 - a) Molde de una figurina femenina procedente de la Plaza III. b) Vasija Inca-Chimú procedente de la píramide IIIA.

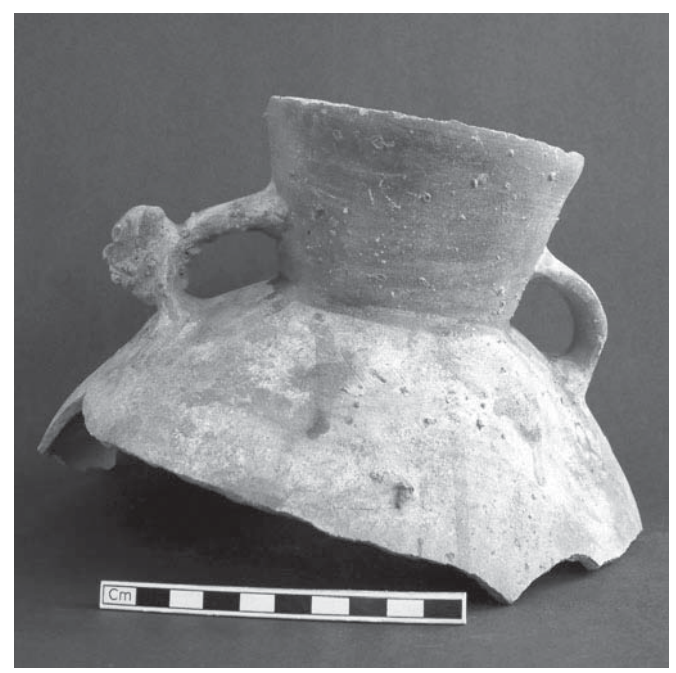

Fig. 3 - Apéndice zoomorfo colocado en el asa de una vasija del Ychsma Tardío de la pirámide IIIA. Nótense las pequeñas manchas de vitrificación en el cuerpo superior. 
Obtenían las arcillas de las colinas y cerros circundantes, aunque todavía no se han descubierto las minas o bancos de arcillas utilizados por los antiguos habitantes de Pachacamac. De estas arcillas creaban varias pastas cuyas inclusiones varían bastante (ver Díaz \& Vallejo, 2002: 58; Paredes \& Ramos, 1989: 330-31; Eeckhout, 1999: 3436). En el pueblo serrano de Santo Domingo de los Olleros mezclan las arcillas de diversas minas para hacer una pasta fina (ver Ramón Joffré, 1999: 226). En aquel pueblo los alfareros le comentaron a la primera autora en 1978 que cuanto más arcillas hay en una mezcla, tanto mejor será la pasta. Se supone que habrán hecho lo mismo en la antigüedad y por esto las inclusiones visibles parecen variar desde cuarzos y feldespatos hasta granitos marrón oscuro (ver Paredes \& Ramos, 1989: 330-331). Todas estas inclusiones se notan en mayores o menores porcentajes, lo que puede resultar en un sinnúmero de pastas para los que quieren clasificarlas (véanse los autores citados arriba). Lo que sí se puede afirmar es que agregaban temperantes a propósito cuando querían fabricar algo poco corriente, por ejemplo un tinajón grande. En este caso agregaban piedrecitas y moluscos de más de un centímetro de largo (Fig. 4a). Si fabricaban una olla sencilla (Fig. 4 b y c), entonces es más probable que las inclusiones se deban a la mezcla intencional de arcillas más que a algún temperante, aunque es

a)

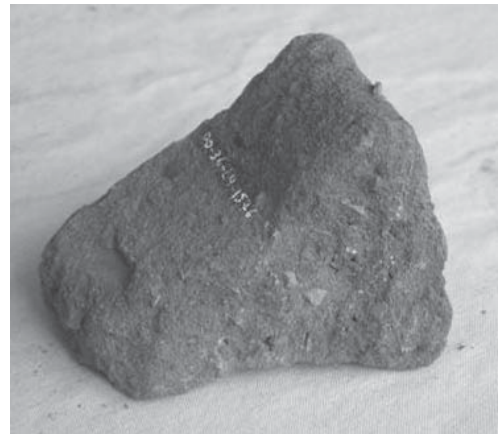

c)

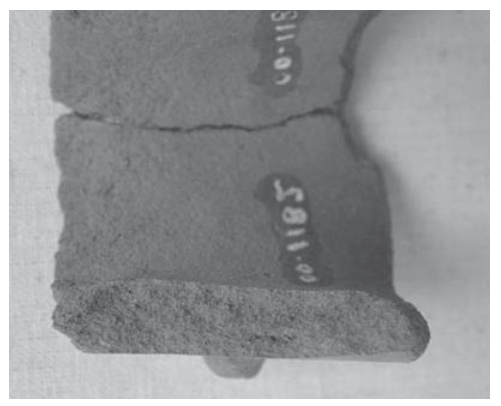

b)

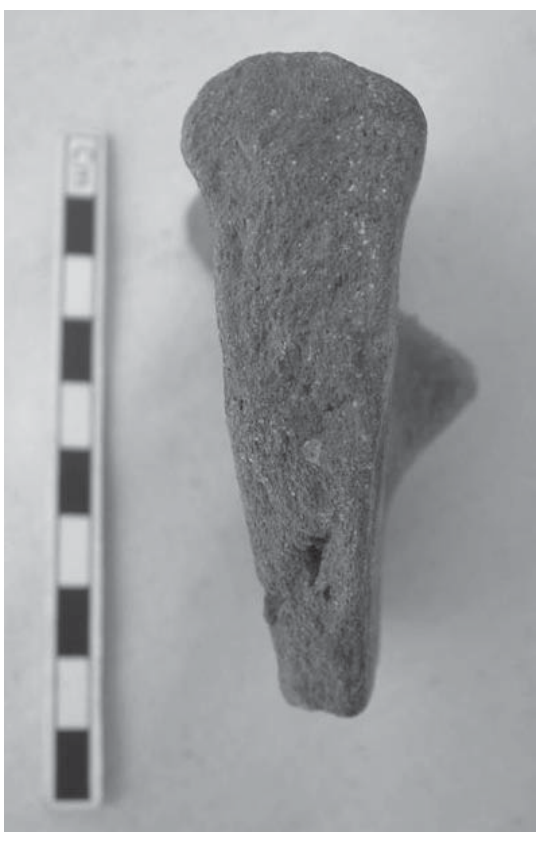

Fig. 4 - Varias pastas del estilo Ychsma: a) pasta para tinajas y tinajones; b) pasta fina; c) pasta corriente empleada para la mayoría de las vasijas. 
verdad que la mayor parte de estas inclusiones parecen ser de cuarzo y a lo mejor provienen de un banco de arcilla cerca de depósitos arenosos (Díaz \& Vallejo, 2002: 58; Paredes \& Ramos, 1989: 330).

Las vasijas fueron cocidas en una atmósfera oxigenante que resultó en un alfar con una gama de colores desde un marrón claro hasta un anaranjado vivo. A veces la cocción es incompleta, resultando en un núcleo gris dentro de la pasta. Muchas veces se notan pequeñas manchas de vitrificación en el exterior de la vasija (véase Fig. 3). Esto podría ser el resultado de estar cubierta de arena durante la cocción; es decir que los granitos de arena se han pegado a la vasija, vitrificándose al ser sometidos a una temperatura alta; o bien puede ser que es simplemente el resultado de la cocción a una temperatura demasiada alta que los alfareros no sabían controlar.

Hemos hablado de dos componentes: uno llano y otro decorado y en efecto la cerámica llana abunda más, pues abarca un $60 \%$ del total. Pero no por esto hay que dejarla de lado porque también evolucionó durante las épocas mencionadas arriba aunque lentamente (Fig. 5). También hay un componente de cerámica negra, cocida en una atmósfera reductora, cuyo porcentaje no supera el $5 \%$ del total durante el Intermedio Tardío. Parece que la cerámica negra se iba haciendo más popular durante el curso de aquella época porque en el Ychsma Tardío aparecen los cuencos carenados negros (Paredes \& Ramos, 1989: fig. 43f) y para el Horizonte Tardío son abundantes nuevas formas y nuevos tipos de decoración, como los cuencos incisos con motivos geométricos (Fig. 6).

Las técnicas de decoración se ven en el cuadro 2. La decoración más frecuente durante el Ychsma Medio y Tardío solía consistir en brochazos de pintura blanca sobre la superficie mate de la vasija que a veces llevaba un engobe rojo (Fig. 7). Los alfareros

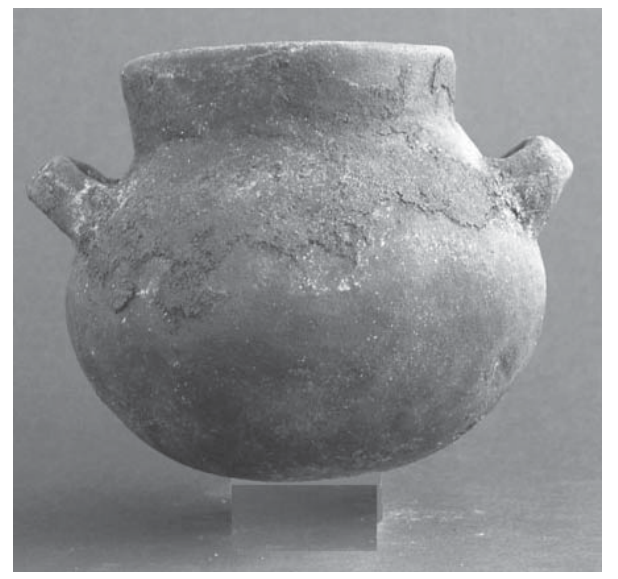

Fig. 5 - Vasija llana del Ychsma Tardío procedente de la pirámide IIIB. Nótense las asas horizontales.

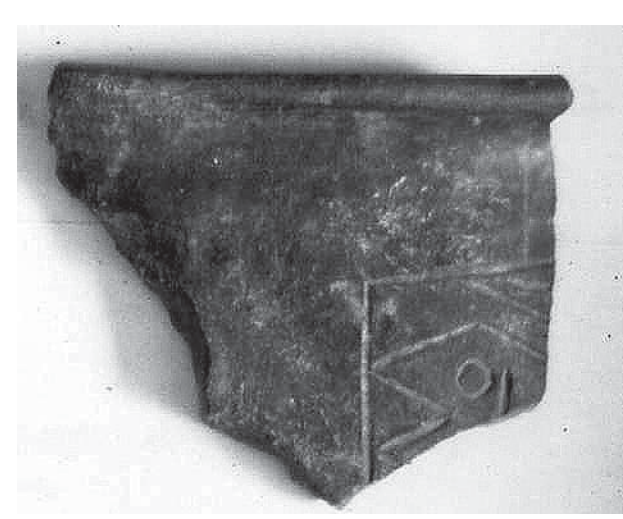

Fig. 6 - Cuenco negro pulido con incisiones pintadas después de la cocción. Es de la superficie de la pirámide IIIB y muestra características del Ychsma Tardío del Incanato. 


\section{Cuadro 2 - Técnicas de decoración.}

\begin{tabular}{|l|l|l|}
\hline 1. Pintura & $\begin{array}{l}\text { a) Blanco sobre el color natural de la pasta } \\
\text { b) Blanco sobre un engobe rojo } \\
\text { c) Negro sobre paneles o bandas blancas sobre el color natural de la } \\
\text { pasta } \\
\text { d) Negro sobre paneles o bandas blancas sobre un engobe rojo }\end{array}$ \\
\hline $\begin{array}{l}\text { 2. Decoración } \\
\text { plástica }\end{array}$ & $\begin{array}{l}\text { a) Estampado } \\
\text { Por medio de la punta de una caña sobre el } \\
\text { color natural de la pasta o sobre un engobe blanco } \\
\text { parcial (8). En las vasijas de negro pulido del Incanato } \\
\text { solían emplear un tipo de cuño, tal vez de madera, } \\
\text { para estampar pequeñas aves o cruces en la superficie } \\
\text { de la vasija } \\
\text { Con un instrumento agudo, tipo buril, se graban } \\
\text { diseños geométricos rellenos de puntos sobre el } \\
\text { color natural de la pasta, o sobre un engobe blanco } \\
\text { parcial }\end{array}$ \\
& $\begin{array}{l}\text { zona Punteado } \\
\text { zona }\end{array}$ \\
\hline 3. Modelado & $\begin{array}{l}\text { Véase el cuadro 1 porque también es técnica de fabricación. Aquí se } \\
\text { refiere a las figuras zoomorfas y fitomorfas como aves, serpientes, } \\
\text { sapos y corontas de maíz que estaban aplicadas sea al cuerpo de la } \\
\text { vasijas, sea a las asas, sea al borde mismo del cuello. }\end{array}$ \\
\hline 4. Moldeado & $\begin{array}{l}\text { También es técnica de fabricación. Algunas aplicaciones como la } \\
\text { "cara boba" (Bazán del Campo, 1992: lámina 31) pueden ser moldeadas } \\
\text { con el resto del cuello. }\end{array}$ \\
\hline
\end{tabular}

también empleaban un tercer color, el negro, con el cual pintaban motivos sobre un panel blanco. Otro rasgo decorativo consiste en una decoración plástica, sea esta un estampado por medio de la punta de una caña (Fig. 8) o bien una decoración incisa con relleno de puntitos que se suele llamar "punteado en zona" o "punzonado inciso" (Fig. 9). Los dos tienen sus antecedentes en los fines del Horizonte Medio/principios del Intermedio Tardío porque unas vasijas de Huallamarca de tipo cara-gollete muestran esta forma de decoración (Fig. 10); sin embargo el primero no era muy frecuente hasta el Ychsma Tardío cuando se hizo muy popular perdurando a través del Horizonte Tardío, pues encontramos bastantes tiestos en las pirámides IIIA y B. Por otra parte el punteado en zona es más frecuente durante la primera parte del Intermedio Tardío, perdiendo su popularidad en Ychsma Tardío y desapareciendo durante el Horizonte Tardío.

Pasamos ahora al Ychsma Tardío que es lo que mayormente encontramos en las excavaciones de 1999 y 2000. ¿Cómo lo diferenciamos del Ychsma Medio descrito por Díaz \& Vallejo, quienes ya dieron unas indicaciones de las características del Ychsma Tardío en su artículo de 2002. Como ya señalamos, los rasgos que citan parecen ser

(8) Se llama engobe parcial porque nunca llega a cubrir la vasija entera. Ver Díaz y Vallejo 2002, sección 3 en las Características de la Producción. 


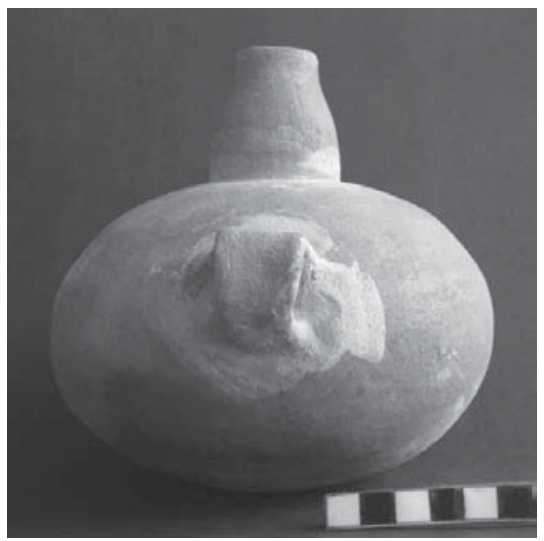

Fig. 7 - Frasco procedente del valle del Lurín con brochazos blancos sobre un engobe rojo.

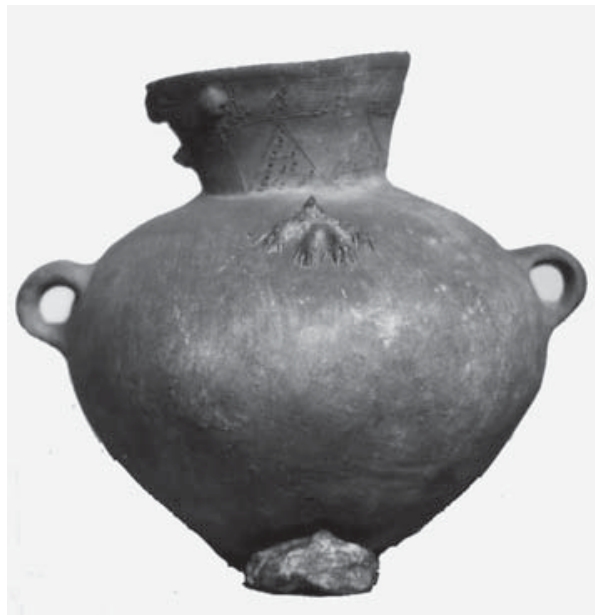

Fig. 9 - Decoración de punteado en zona sobre una vasija de Pachacamac. Fue excavada por Adolphe Bandelier en el cementerio $n^{0}$ I delante del Templo Pintado.

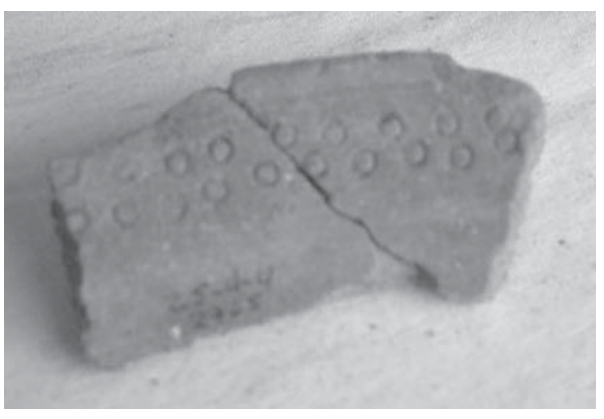

Fig. 8 - Decoración estampada con punta de caña. El tiesto viene de la píramide IIIB.

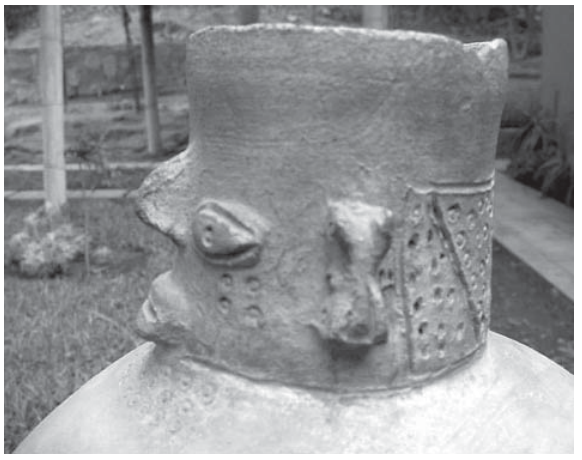

Fig. 10 - Vasija de Huallamarca de fines del Horizonte Medio con caragollete y decoración punteado en zona y estampado. 
coetáneos con lo incaico pero nosotros creemos que la evolución del Ychsma Medio al Ychsma Tardío tuvo lugar un poco antes de la conquista Inca, o sea a fines del siglo catorce según los fechados radiocarbónicos para la píramide IIIB. En efecto el rasgo que más lo define es el mayor uso por parte de los alfareros de diseños blancos y negros sobre un engobe rojo hacia fines del Intermedio Tardío. Muchos autores llaman Inca Asociado a este estilo de blanco y negro sobre rojo (Franco Jordán, 1998: fig. 46, nº 2, 4, 20) o black and white on red style (Strong \& Corbett, 1943: 60, fig. 12 c-f), pero nos parece que sus raíces se encuentran ya en el Intermedio Tardío. Se trata de un florecimiento de motivos que antes se limitaban a lo geométrico (líneas o rayas negras sobre una banda blanca (Fig. 11) y ahora incluyen aves, peces, rombos, escalones y triángulos. Es verdad que el engobe rojo ha sido empleado a partir de los fines del Horizonte Medio, pues se notan vasijas con este color de engobe en las colecciones de Bandelier de Pachacamac y de Huallamarca (Fig. 12) de Arturo Jiménez Borja, pero nos parece que hacia fines del Intermedio Tardío, durante la segunda mitad del siglo catorce, el engobe rojo se hizo mucho más popular.

En cuanto a los diseños en blanco y negro sobre rojo, estos también se remontan hasta principios del Intermedio Tardío como se ve en las láminas de Uhle (1903: lams. $8,2-4,6)$, pero los motivos suelen ser muy geométricos, es decir líneas paralelas rectas o en zigzag con pequeñas rayas o puntitos dentro de los espacios (ver Fig. 11); o bien unas líneas cruzadas para formar un tipo de enrejado (Díaz \& Vallejo, 2002: 54, fig. 3). Estos diseños se realizaban sobre el color naranja de la pasta misma según se nota en una vasija procedente de las excavaciones de Díaz y Vallejo en Armatambo (Díaz \& Vallejo, 2002: fig. 3) y según se ha visto en algunos ejemplos del valle del Rímac que se

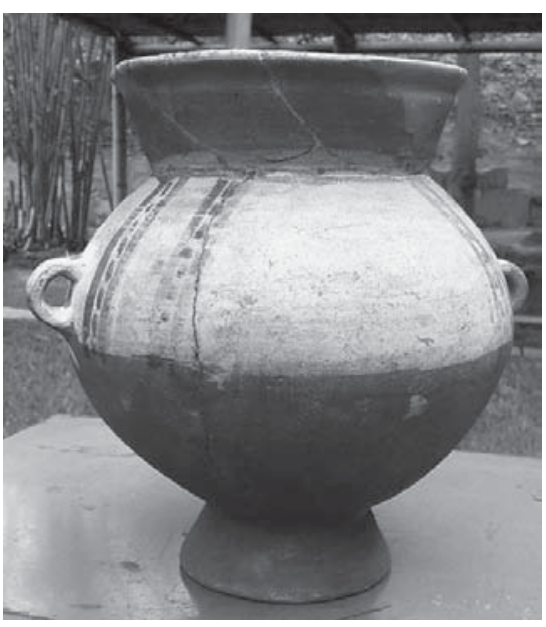

Fig. 11 - Vasija de Huallamarca con decoración negro sobre blanco sobre engobe rojo. Nótense los motivos sencillos, geométricos.

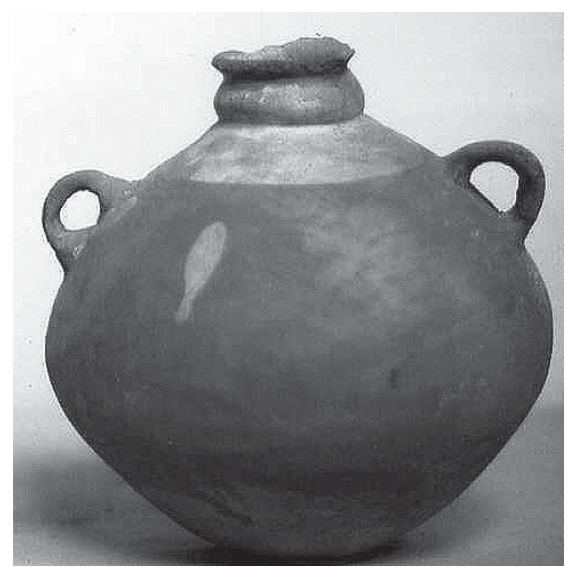

Fig. 12 - Vasija de Pachacamac excavada por Adolphe Bandelier con engobe rojo y pintura blanca. 
encuentran en el Museo de Historia Natural de Nueva York. Las formas más notables del Ychsma Tardío son los cuencos carenados que exhiben los motivos nuevos mencionados arriba (Fig. 13) y las jarras con cara-gollete (Fig. 14) ( $c f$. Franco Jordán, 1998: figs 43, 7-13 y 44). Como ejemplo de las diferencias entre el Ychsma Medio y el Ychsma Tardío un pequeño frasco que se encontró en la Pirámide III (Fig. 15) cuya forma recuerda algunas de Las Palmas (Paredes \& Ramos, 1989: fig. 19). Se notan los brochazos blancos sobre un engobe rojo. En la figura 16, que es del Ychsma Tardío, vemos el mismo tipo de frasco con diseños en negro sobre blanco (muy deteriorados) sobre lo que parece ser un engobe rojo.

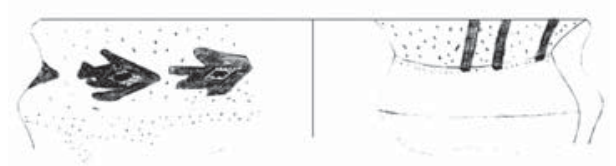

Fig. 13 - Dibujo de cuenco carenado de la Plaza V de la pirámide IIIB con motivo de peces.

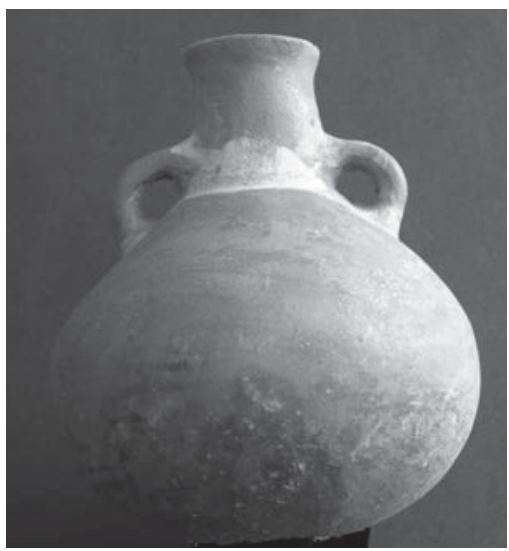

Fig. 15 - Pequeño frasco procedente de la pirámide IIIA.

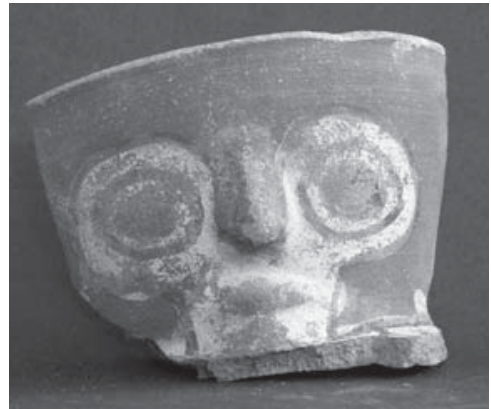

Fig. 14 - Cara-gollete de la Plaza II del complejo piramidal III.

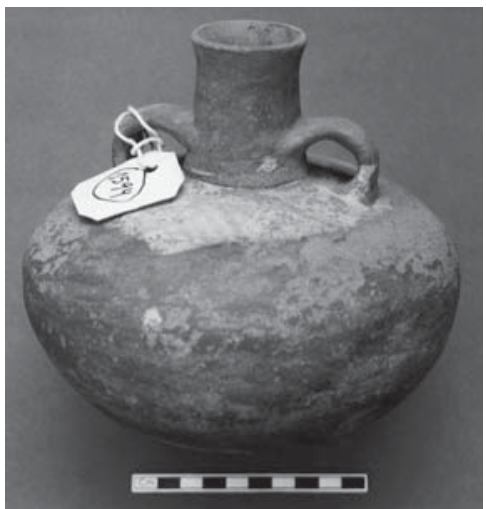

Fig. 16 - Pequeño frasco de Armatambo semejante a la figura 15 , con decoración en negro sobre blanco sobre rojo. 
Las excavaciones en las piramides A y B dentro del complejo piramidal ya mencionado nos han proporcionado bastantes datos sobre el Ychsma Tardío. Es verdad que algunos rasgos pueden atribuirse a la influencia Inca, pero otros se deben igualmente a la evolución del estilo, quizas debido a mayores contactos foráneos a causa de la creciente influencia y prestigio de Pachacamac hacia fines del Intermedio Tardío. Según se explicó arriba, el estilo Ychsma Tardio duró desde fines del siglo catorce hasta las primeras décadas de la Colonia. Los tiestos del estilo cuzqueño de los incas y unos contados tiestos coloniales en las pirámides confirman esto. A continuación se presentan algunos datos sobre el estilo.

En cuanto a las formas, para fines de una descripción adecuada, solemos repartirlas entre 6 clases: los platos, los cuencos, las jarras, los frascos y botellas, las tinajas y tinajones y las vasijas en miniatura (9). En el Ychsma Tardío no hay platos pero tampoco los hubo en el Ychsma Medio, ni hubo cuencos. Por otra parte, en el Ychsma Tardío los cuencos son bastante frecuentes en las plazas de las pirámides. Los tiestos son lo bastante grandes como para suponer que muchos cuencos fueron rotos a propósito durante algún rito. Se llaman cuencos carenados por el ángulo de carenación cuya línea queda bien marcada en el exterior (Figs. 17 y 18a). Suelen llevar un engobe rojo y luego una capa de pintura blanca en la parte superior y sobre esta capa han pintado un diseño de pequeños rectángulos con un punto dentro, o de triángulos, o de peces (Fig. 18b). Si tienen un pequeno reborde, este suele llevar grupos de líneas negras en el interior (Fig. 18d). Este es el tipo de cuenco más frecuente en el Ychsma Tardío. Más tarde durante el Incanato fabricaron otras formas de cuencos además de los cuencos carenados pero, como aquellos tienen una clara relación con lo incaico no serán tratados aquí. A veces hay un sapo o un ave modelada en la carenación o sobre el borde del cuenco (Fig. 18c), pero parece que estos elementos decorativos también son del Incanato ( $c f$. Isla, 1995: figura 3a-3c).

Hay vasijas cerradas que muchos reparten entre ollas y cántaros, teniéndose en cuenta su función o de almacenar líquidos o de ser empleados para cocinar. Preferimos no decir nada sobre su función mientras que esta no esté clara y por lo tanto las llamamos todas jarras, siendo vasijas cerradas las que llevan algún tipo de cuello. Este cuello puede ser recto divergente, la más popular de todas las formas, la cual se encuentra con muchas variaciones. A veces el cuello tiene un alto de $10 \mathrm{~cm}$ y es ligeramente evertido; otras veces es mucho más bajo (Fig. 19). En Ychsma Medio el labio de estas vasijas suele ser redondo, ligeramente afilado, a veces biselado hacia el interior o ligeramente evertido (ver Diaz \& Vallejo, 2002: formas 17, 18, 19, 20, 22). En Ychsma Tardío continúan estas formas de labios, pero se agregan otros tipos de labios, aplanados, y más evertidos (Fig. 20) (10). En el Ychsma Medio muchas veces estas formas no llevan decoración, si no es una pintura burda, blanca sobre el color natural de la pasta o un engobe rojo. Esta pintura consiste en bandas blancas alrededor del cuello o del labio, o alrededor de la base de las asas (Fig. 21). En Ychsma Tardío empieza la costumbre artículo.

(9) Para una mayor explicación sobre estas formas, véase en el texto, la nota al final de este

(10) Cf. Bazán del Campo, 1992: láminas 16a, 18a; Franco Jordán, 1998: figura 46-1; Silva, 1992: figuras $70,86,95,101$. 


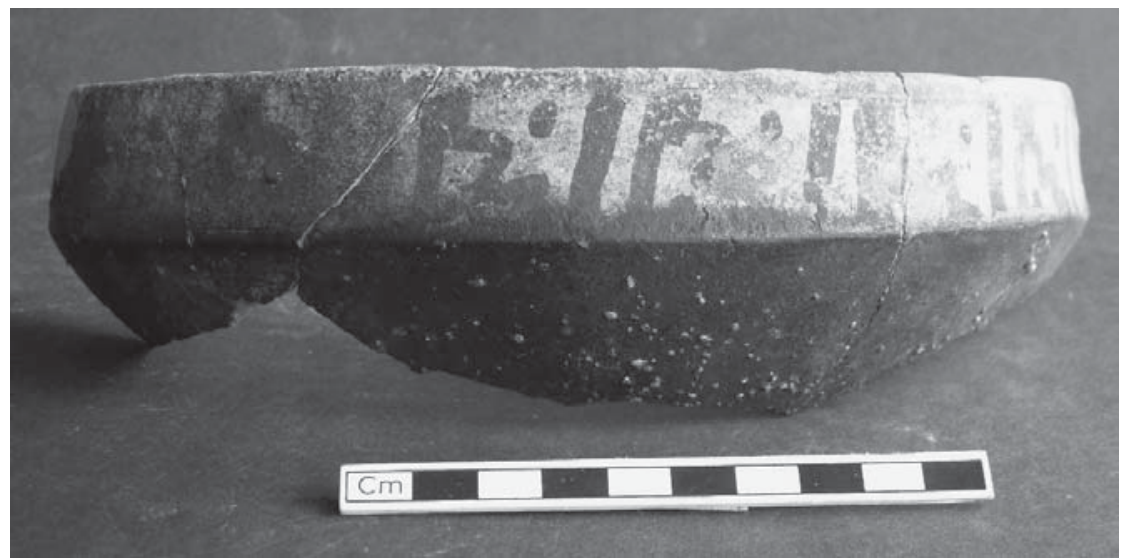

Fig. 17 - Cuenco carenado sin reborde de la pirámide III B.
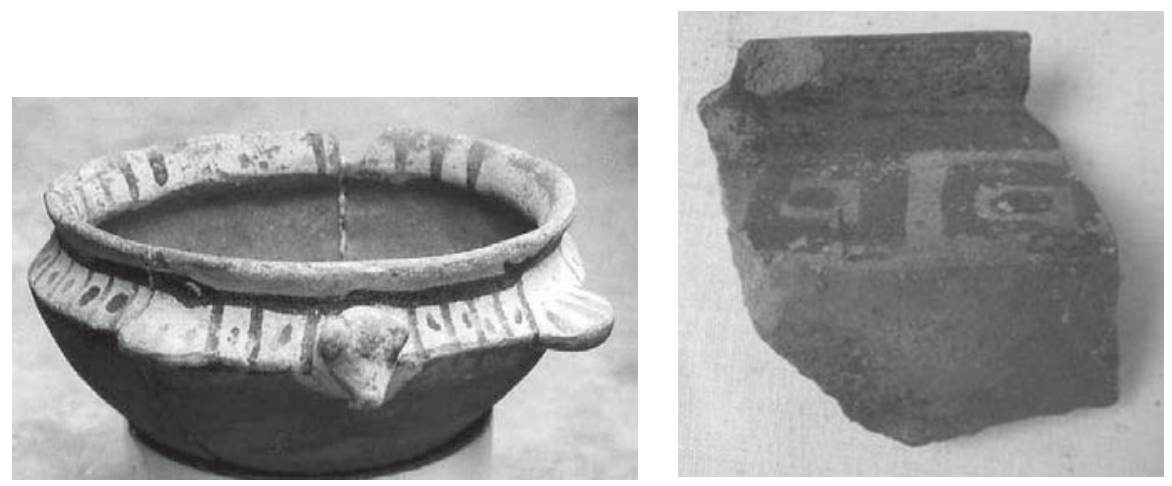

a)

b)

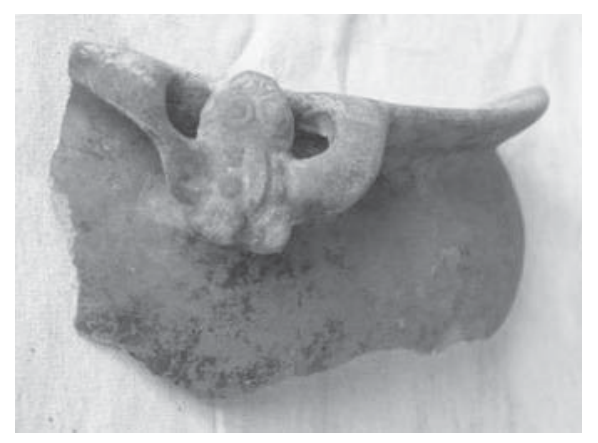

c)

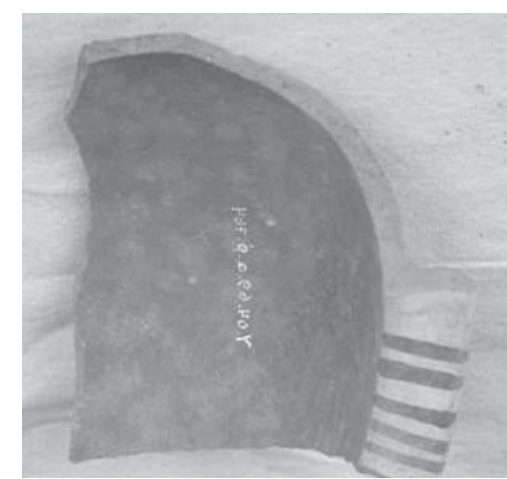

d)

Fig. 18 - Cuencos carenados con reborde. a) cuenco entero; b-d) tiestos procedentes de la pirámide IIIB. 


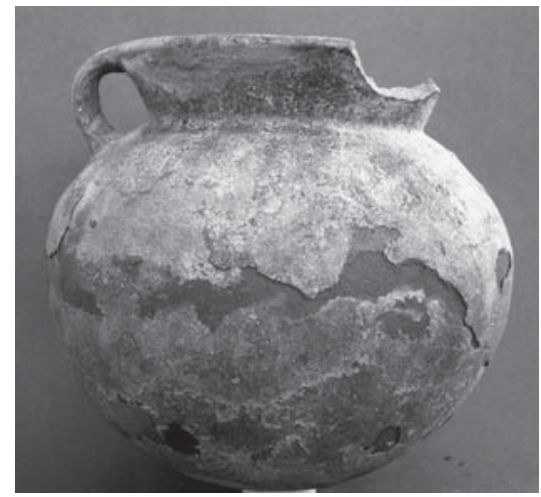

Fig. 19 - Jarra con cuello recto divergente procedente de la limpieza del muro sur de la Plaza III.

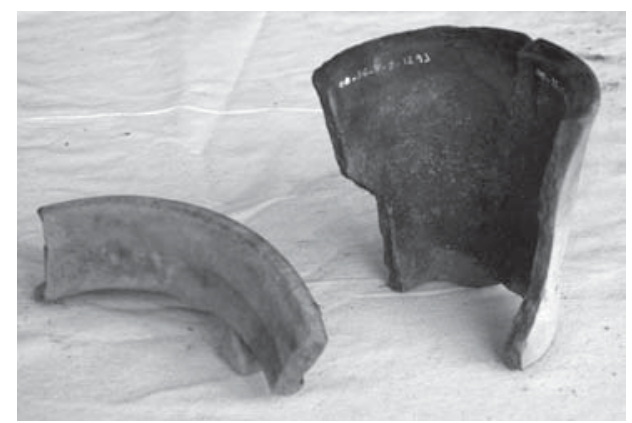

Fig. 20 - Tiestos que muestran labios aplanados típicos del Ychsma Tardío. Vienen de la Plaza II.

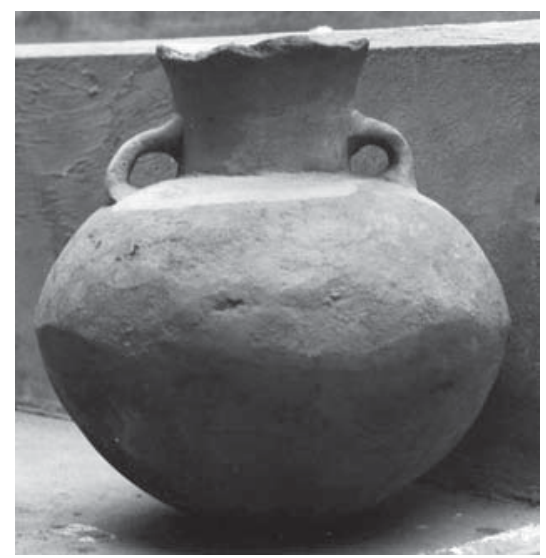

Fig. 21 - Jarra con pintura burda en la forma de brochazos sobre el color natural de la pasta. Viene de la pirámide XIII. 
de pintar bandas blancas verticales sobre el cuerpo de la vasija (Fig. 22). Más tarde en el Incanato estas bandas son más anchas cubriendo la mitad de la superficie del cuerpo de la vasija (Fig. 23).

Ya hablamos de la decoración de punteado en zona, que está más vinculada al Ychsma Medio e Ychsma Temprano. Consiste en colocar en el cuerpo o en el cuello de la vasija unas líneas incisas en forma de triángulos o líneas paralelas en zigzag, cuyo campo interior ha sido punteado con algún instrumento agudo. Parece que esta forma de decoración se remonta por lo menos hasta principios del Intermedio Tardio (Franco Jordán, 1998: 70, cuadro 1; Feltham, 1983: 717-718; Eeckhout, 1999: 74, cuadro 4.17). Uhle encontró algunas vasijas de este estilo en el cementerio I, aunque no menciona más que una en su obra (Uhle, 1903: lamina 8, fig. 9). Las formas tempranas en las que se encuentra esta decoración son tipos de cara-gollete (véase Fig. 10) o vasijas con cuello abombado (Fig. 9). Para Ychsma Medio la decoración se limita a triángulos y líneas zigzagueantes o paralelas en el interior de un cuello evertido (Díaz \& Vallejo, 2002: formas 18 B, C, D; Franco Jordán, 1998: figura 39-1, 2). Son únicamente las líneas paralelas en zigzag (Fig. 24) que continuaron en el Ychsma Tardío. Estas líneas siempre se encuentran en el interior del cuello y no en el exterior de los cuellos, como en los cuellos abombados y las cara-gollete del Ychsma Temprano o Inicial (Figs. 9 y 10).

Las vasijas llanas sin decoración continuaron en el Ychsma Tardío; muchas veces son de cuello recto con asas horizontales que no suelen ser decoradas (Fig. 5). Anteriormente en Ychsma Medio eran completamente llanas o llevaban un engobe blanco parcial o completo (Fig. 28). Lo que es bastante popular es el cuello abombado

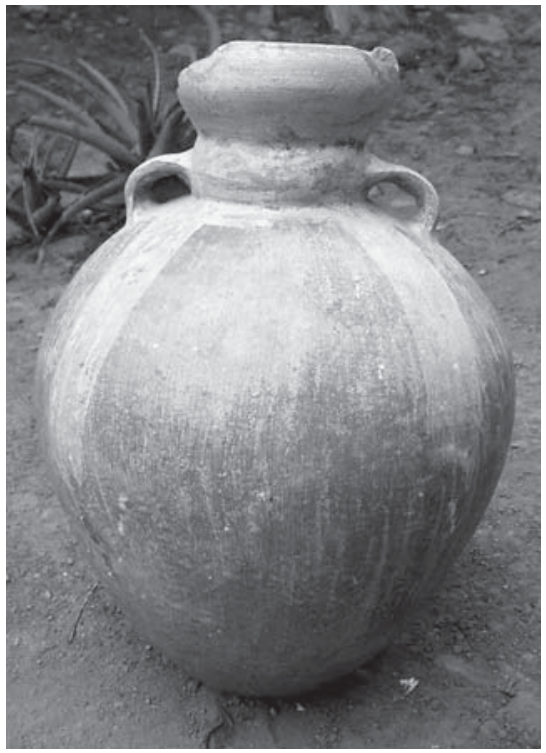

Fig. 22 - Jarra de Huallamarca del Ychsma Tardío que muestra bandas blancas verticales.

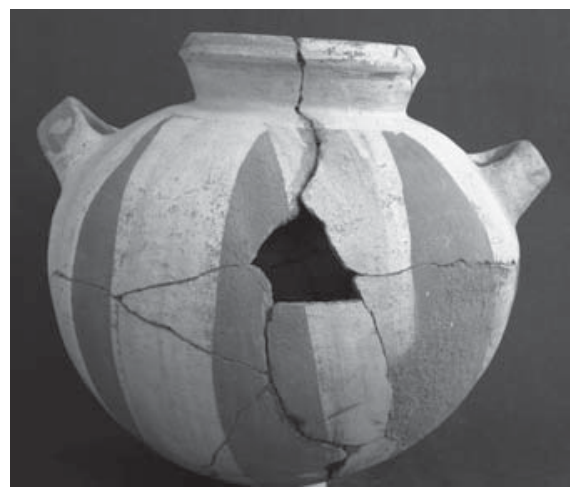

Fig. 23 - Jarra con labio en forma de "media flecha" con las bandas blancas del Incanato. Viene de la pirámide IIIA. 
que tiene la forma de un pequeño barril o copa colocada sobre el cuerpo de la vasija (Fig. 25). En el Ychsma Medio, según se nota por ejemplo en Armatambo y las colecciones de Adolfo Bandelier de Pachacamac, estos cuellos solían ser más altos (Fig. 26; Díaz \& Vallejo, 2002: forma 14 A) (11), mientras que en el Ychsma Tardío siempre son más bajos (Uhle, 1903: figs. 84 y 85; nuestra figura 25; Bazán del Campo, 1992: lámina 9f, 23d, 26c; Franco Jordán, 1998: figura 46-5; Silva, 1992: figs. 89, 93, 154.2). En el Ychsma Medio a veces llevan un asa que une el punto medio del cuello con la parte superior del cuerpo (Díaz \& Vallejo, 2002: forma 11). En el Ychsma Tardío esta forma nunca lleva decoración de punteado en zona, como ocurre en el Ychsma Temprano y Medio. Puede ser completamente llana o llevar una decoración de bandas blancas sobre un engobe rojo, tal como se ve en la vasija de la figura 27, la cual es del Incanato porque

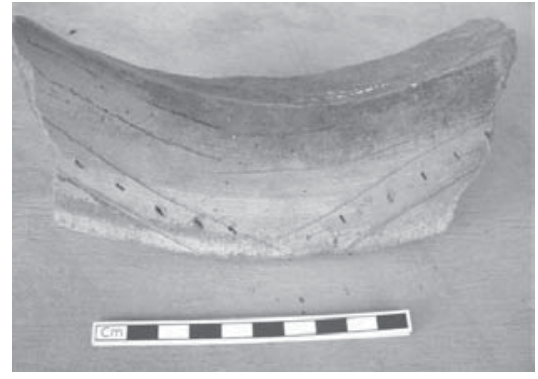

Fig. 24 - Tiesto de la Plaza III que muestra el interior de un cuello evertido con decoración de punteado en zona. Las líneas paralelas zigzagueantes tienen un relleno de puntitas.

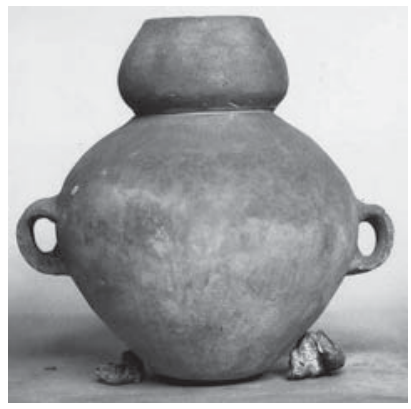

Fig. 26 - Jarra llana del Ychsma Medio, procedente de las excavaciones de A. Bandelier en el cementerio $n^{0} 1$ de Pachacamac. El cuello ambombado más alto y con menor diámetro que el de la Fig. 25.

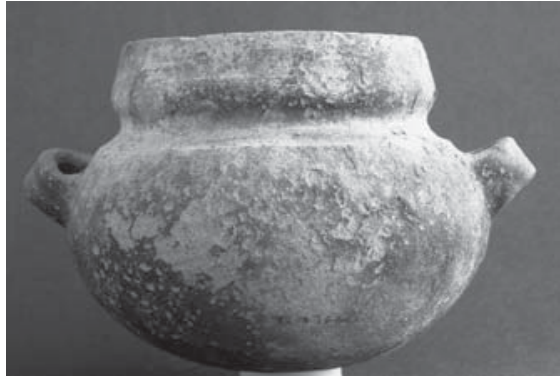

Fig. 25 - Jarra llana del Ychsma Tardío, procedente del valle del Lurín con cuello abombado. Nótense las asas horizontales.

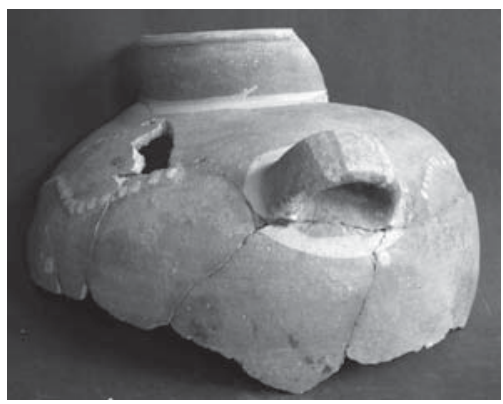

Fig. 27 - Jarra con engobe rojo y decoración blanca con cuello abombado. Es del valle del Lurín y del Incanato porque lleva serpientes modeladas.

(11) Tambíén los hay bajos en el Ychsma Medio (Díaz \& Vallejo, 2002: formas 6 y 14) pero los cuellos abombados bajos prevalecen en el Ychsma Tardío. 
lleva un par de culebras modeladas en la parte superior del cuerpo (Fig. 27). Las serpientes pueden ser combinadas con pequeñas protuberancias que forman dos filas a cada lado de la serpiente (Uhle, 1903; Bazán del Campo, 1992: fig. 32a).

Los cuellos compuestos también se remontan al Ychsma Temprano (Feltham, 1983: 533) y al Ychsma Medio pues se encuentran en las excavaciones de Adolphe Bandelier y de Squier (Fig. 28). La de Squier se parece a una forma descrita por Díaz \& Vallejo de Armatambo (2002: forma 7 y Fig. 7) con asas verticales, un engobe blanco y un diametro de boca entre 12 y $14 \mathrm{~cm}$. En el Ychsma Tardío, el cuerpo es más redondeado, las asas son horizontales y si hay engobe, este es rojo (Fig. 29). Hay que notar también otra variedad del cuello compuesto en el Ychsma Tardío según se ve en nuestra figura 22, en que el cuello y la disposición de las asas son muy parecidos a los del estilo Chancay. En el Ychsma Medio estos cuellos compuestos pueden ser mucho más pequeños, con el diámetro de un frasco más que una jarra (Fig. 12).

Otra forma de interés que parece ser exclusivamente del Ychsma Tardío del Incanato es la que llamamos "la media flecha". Consiste en un cuello recto o ligeramente evertido con un labio muy aplanado y biselado al exterior para dar un perfil de la mitad de una flecha (Figs. 23 y 30). Muchas veces suele ser cubierta con una capa de pintura blanca sobre el interior y el exterior del cuello encima de un engobe rojo según se ve en la figura 30a. Otro método de decoración es el estampado con punta de caña, consistiendo en dos o tres filas de círculos hechos con la punta de una caña y dispuestos alrededor del hombro de la vasija, un poco debajo del cuello o en el interior del cuello (Fig. 31). Esta forma de decoración es bastante tardía y se parece mucho a la descrita por Bonavia en Puerto Viejo, Chilca (Bonavia, 1959: lámina XI) donde la mayoría de la cerámica tiene semejanzas con el Ychsma Tardío. Durante el Incanato esta forma de vasija a veces lleva serpientes modeladas del mismo modo que las otras formas descritas arriba.

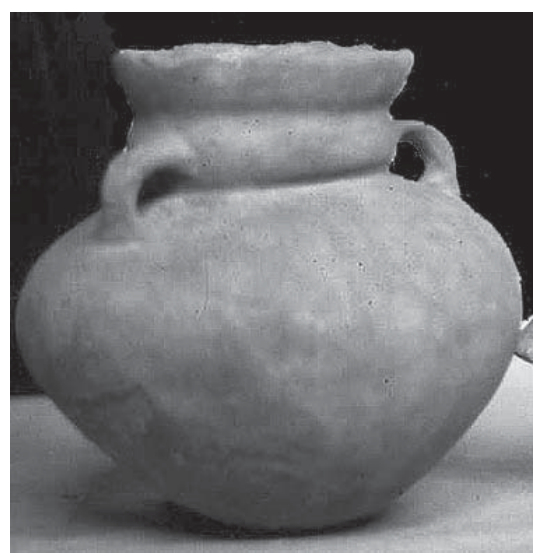

Fig. 28 - Vasija del Ychsma Medio con cuello compuesto y engobe blanco encontrada por Squier en una tumba de Pachacamac.

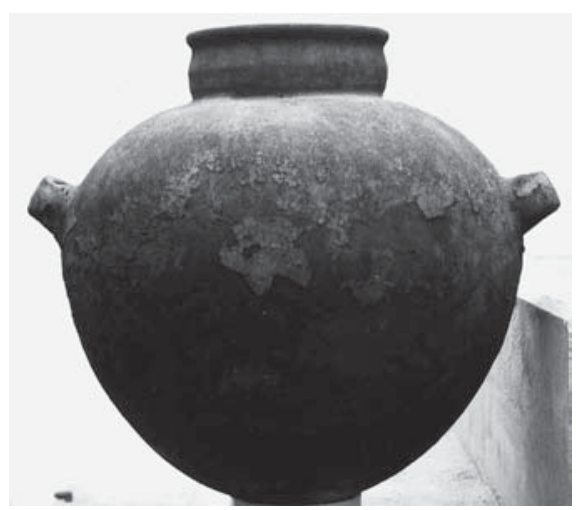

Fig. 29 - Vasija con cuello compuesto de la piramide VIII. Es del Ychsma Tardío. Nótense las asas horizontales. 
a)

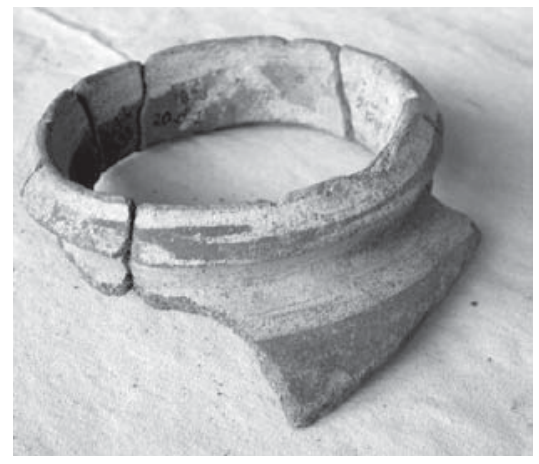

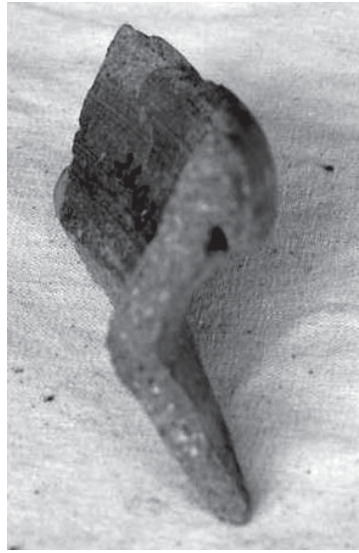

b)

Fig. 30 - Dos ejemplos del cuello de "media flecha" del Ychsma Tardío del Incanato. Vienen de la Plaza III.

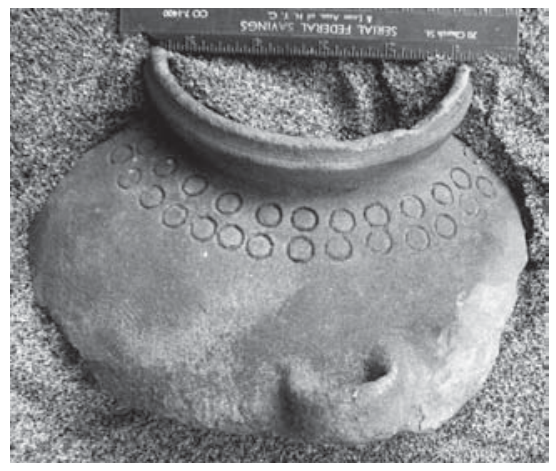

Fig. 31 - Vasija del Ychsma Tardío con cuello abombado y decoración de estampado por puntita de caña. Viene del valle del Lurín.

También destaca el hecho de que muchas vasijas del Ychsma Tardío llevan asas horizontales, lo cual es poco común en el Ychsma Medio. Cuando repasábamos unas colecciones conocidas del Ychsma Temprano, como Huallamarca, y del Ychsma Medio en Armatambo, pudimos constatar que la mayoría de las vasijas, cuando llevan asas, las llevan verticales en el diámetro máximo de la vasija, o partiendo de un punto a la mitad del cuello y terminando en el hombro superior de la vasija (Fig. 32; Díaz \& Vallejo, 2002: formas 11, 15 y la figura 4). En el Ychsma Tardío creemos que iba prevaleciendo una preferencia para las asas horizontales (véase, por ejemplo, Uhle, 1903: 66, figs. 8485) (12). Otro rasgo característico del Ychsma Tardío, ya comentado por Díaz \& Vallejo

(12) Esto no caracteriza las vasijas de clara morfología Inca como las que se ven en las páginas 64 y 65 de Uhle, las cuales llevan asas verticales; tampoco se nota en las vasijas "cara-gollete". Tampoco quiero decir que todas las jarras del Ychsma Tardío llevaban asas horizontales, sino que en 
(2002: 70), son las asas cintadas que unen el labio mismo con la parte superior del cuerpo (Fig. 19) a diferencia de las del Ychsma Medio. Nos parece que en la primera fase del Ychsma Tardío el labio sigue siendo redondo o ligeramente aplanado, mientras que más tarde en el Incanato el labio llega a ser muy plano.

Pasamos ahora a las vasijas más conocidas del estilo, la cara-gollete, las cuales parecen ser fuertes marcadoras del Ychsma Tardío (Bueno, 1978: 68; 1982: 41-42). Estas tienen una cara modelada en el cuello, con orejas/y o orejeras, nariz, boca y ojos, siempre en negro sobre blanco sobre un engobe rojo que cubre toda la vasija (Figs. 14 y 33). La cara es blanca y las facciones quedan pintadas de negro. El cuello es alto, ligeramente evertido y el labio puede ser plano con una ligera eversión o redondo. En el cuerpo de la vasija hay brazos pintados (a veces modelados también) con manos que se juntan sobre el vientre (Uhle, 1903: lámina 13, fig. 6; Isla, 1995: 6d; Hyslop \& Mujica, 1992: fig. 20; Bazán del Campo, 1992: láminas 16b, 29, 30; Franco Jordán, 1998; figura 45-15,17; Hyslop \& Mujica, 1992: 61, fig. 20). Muchos quieren ver estas vasijas como manifestación del Incanato pero creemos que están arraigadas en el Ychsma Tardío un poco antes de la incursión de los incas. Parece que durante el Incanato, estas vasijas tenían más variedad en la cara (Uhle, 1903: lámina 13, fig. 4, 5, 7; Isla, 1995: fig 6), pues una cara sonríe, y otra lleva las manos a los sienes de la misma manera que unas vasijas de Chincha que pertenecen a la última fase del Intermedio Tardio (Kroeber \& Strong, 1924: plate 12d). Según hemos visto, las colecciones de Huallamarca y de Bandelier en Pachacamac contienen vasijas cara-gollete (Fig. 9). Algunas de estas vasijas tienen una clara relación con las del Horizonte Medio, y son algo parecidas a la descrita por Uhle (1903: lámina 7-1). Otras son más tardías y tienen una decoración de punteado en zona.

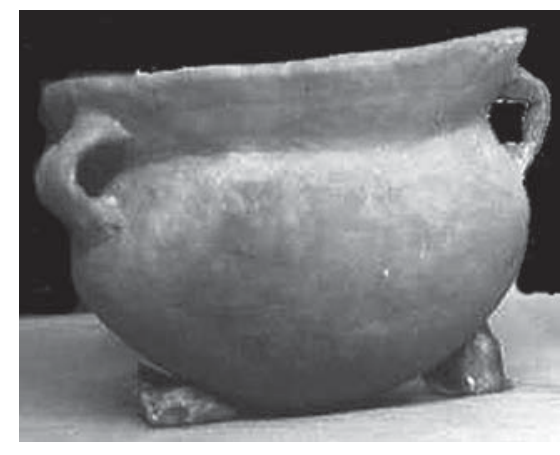

Fig. 32 - Vasija de cuello recto con asas que unen la porción media del cuello con la parte superior del cuerpo. Viene de Pachacamac.

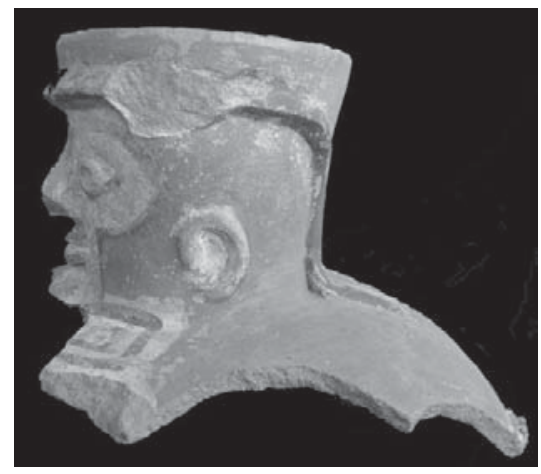

Fig. 33 - Vasija cara-gollete de la Plaza II.

algunas formas de jarras sencillas las asas horizontales iban prevaleciendo. Algunas vasijas de Ychsma Medio llevaban asas horizontales (Díaz \& Vallejo, 2002: figura 3) pero no son muy frecuentes. Hemos visto un solo ejemplo en las colecciones de Huallamarca y no las hay entre las 231 vasijas excavadas por Bandelier en el cementerio $n^{\circ} 1$ de Pachacamac. 
Es probable que las pintadas, descritas aquí del Ychsma Tardío son las descendientes de aquellas pero todavía no sabemos si la cara representa a algún dios o a varios dioses o si no tiene nada que ver con la religión.

La cuarta clase de vasijas son las tinajas y tinajones que se encuentran con frecuencia en las plazas de las píramides. Parece que allí mismo fueron fabricadas, porque hemos encontrado desechos de la fabricación y algunas herramientas. No hemos descubierto ninguna tinaja o tinajón entero en la píramide III, solo fragmentos grandes, y por esto su reconstrucción es todavía problemática. Llamo tinajas a vasijas de alrededor de medio metro o más de alto con un borde de más de $30 \mathrm{~cm}$ de diámetro. Las paredes de estas vasijas son bastante gruesas alcanzando un mínimo de $1 \mathrm{~cm}$ de grosor (Fig. 34a). Como no son fácilmente portátiles, se supone que fueron rotos in situ. La forma más popular en el Ychsma Tardío tiene un cuello ligeramente abultado con un labio engrosado y plano (Fig. 35). En el estado actual de nuestros conocimientos parece que en el Ychsma Tardío no hay mucha evolución desde el Ychsma Medio. Hay tinajas con cuello evertido, generalmente llanas o con pintura blanca chorreada sobre el exterior del cuello (Díaz \& Vallejo, 2002: forma 36); otras con cuello convergente (Díaz \& Vallejo, 2002: forma 34A); y otras como la forma 38. También hay de tipo pepino que se suele asociar con el Incanato (Uhle, 1903: 63, fig. 66; Hyslop \& Mujica, 1992: fig. 19). Los tinajones son vasijas tan grandes que no fueron fabricadas con frecuencia porque se esperaba que iban a durar mucho tiempo. Estos tienen paredes de más de $2 \mathrm{~cm}$ de grueso (Fig. 34b) con una altura más de un metro y medio, de modo que una persona podía caber dentro. El borde de los tinajones suele ser muy sencillo, con una forma de coma (Fig. 36) o parecido al de Díaz \& Vallejo (2002: formas 37 y 38).

Las últimas clases que vamos a tratar son los frascos, botellas y vasijas en miniatura. En el Ychsma Medio aquellos pueden tener un cuello alto, recto o ligeramente evertido (Díaz \& Vallejo, 2002: formas 1 y 2) o pueden ser abombado (Díaz \& Vallejo, 2002: forma 3). Parece que estos tipos siguieron siendo fabricados durante el Ychsma Tardío (Fig. 37) pues se encuentran como ajuar funerario en asociación con vasijas del Ychsma Tardío. Es cierto que servían para ofrendas o ajuar funerario más que para uso diario (véase Paredes \& Ramos, 1989: 326 y figura 19). El cuello puede ser ligeramente evertido o abultado y es de corto diámetro, entre 4 y $8 \mathrm{~cm}$. En el Ychsma Tardío, a veces están decoradas con pintura negra y blanca sobre un engobe rojo (Fig. 16), o pueden ser llanas con brochazos blancos o bandas blancas verticales (ver Uhle, 1903: 66, fig. 86).

Los incas introdujeron la forma de botella al estilo Ychsma. Son siempre fabricadas en molde, en pastas gris y naranja, pero mucho más finas que las del Ychsma corriente, siguiendo las pautas Chimú, para dar luz a un estilo híbrido que llamamos Inca/Ychsma/Chimú (Figs. 2b y 38). Suelen ser del tipo asa estribo. A diferencia del estilo Ychsma, tales botellas nunca tienen un acabado mate, pero siempre fueron bruñidas para dar un lustre muy atrayente. En ese sentido no forman parte del verdadero estilo Ychsma y serán tratadas en otra ocasión. En cuanto a las vasijas en miniatura, se consideran ofrendas y su forma es muy sencilla. Suelen no llevar decoración sino de vez en cuando algunos brochazos blancos (Fig. 39). Nos parece que la forma de estas vasijas en miniatura no ha cambiado desde el Ychsma Medio.

Esto, en resumen, es la clase de cerámica que compone el Ychsma Tardío. Se nota que no hemos tratado ninguna cerámica de pasta gris ni las formas que siguen una 
a)
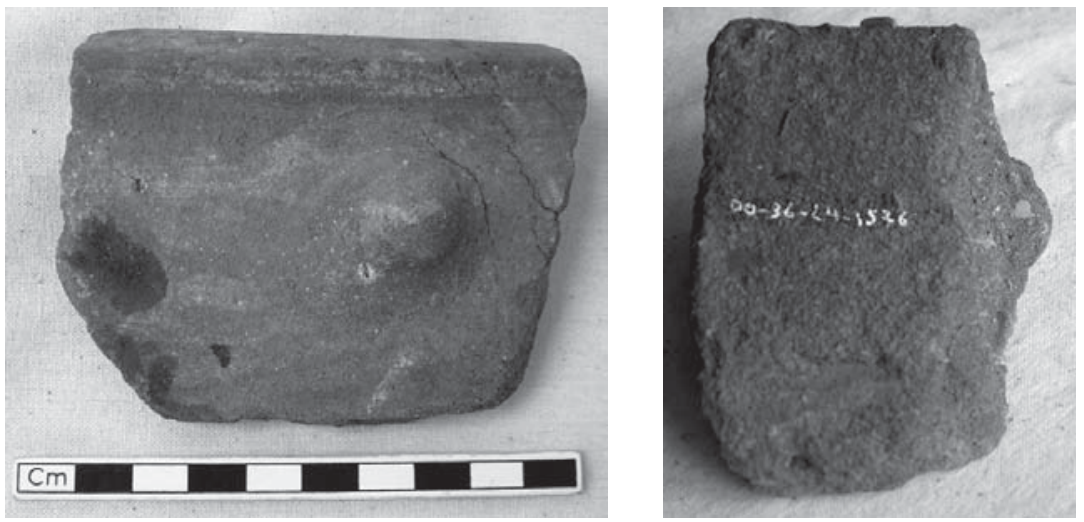

b)

Fig. 34 - Tinaja y tinajón de la Plaza II.

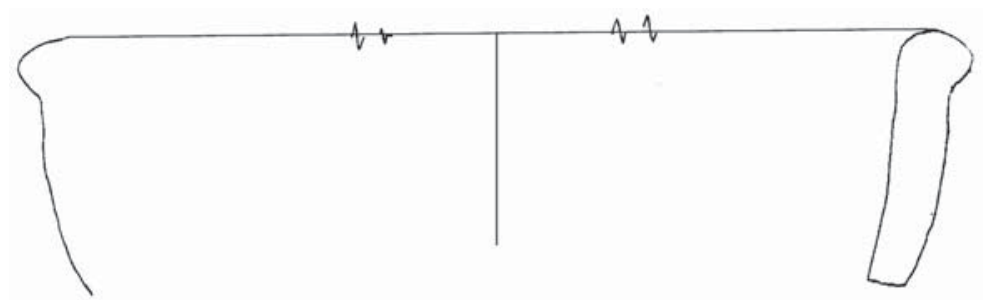

Fig. 35 - Dibujo del borde de una tinaja, tipo E I c.

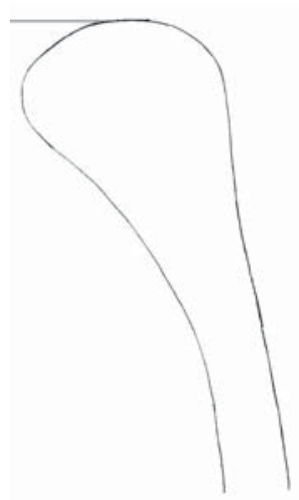

Fig. 36 - Dibujo del borde de un tinajón.

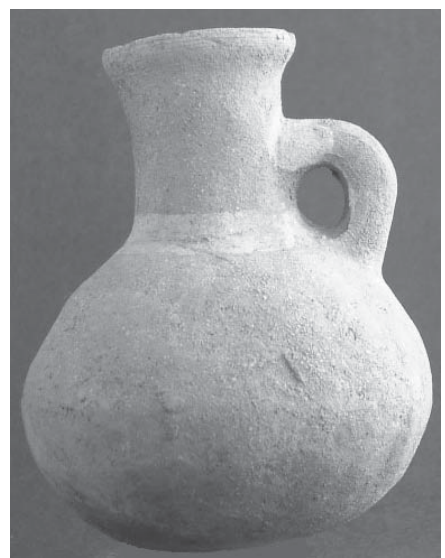

Fig. 37 - Pequeño frasco de la Plaza II, unidad 43, entierro tardío. 


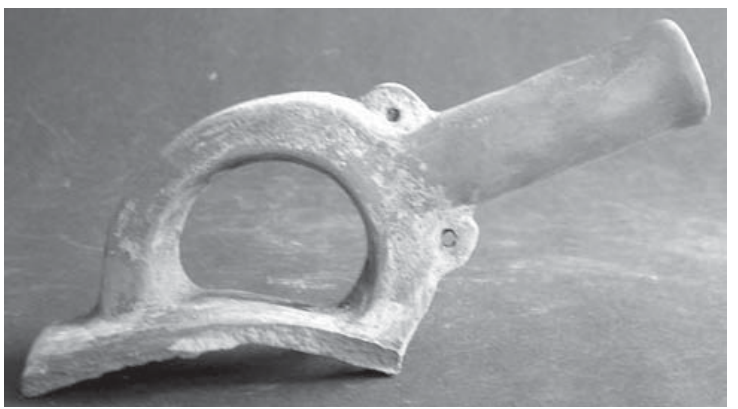

Fig. 38 - Asa estribo de botella naranja pulido del estilo Inca-Ychsma-Chimú.

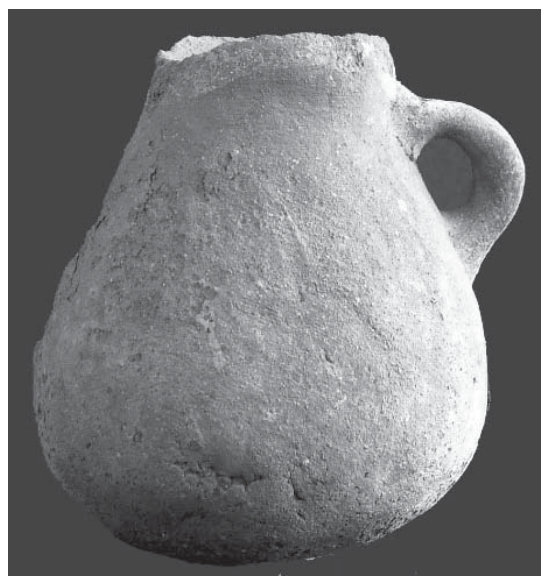

Fig. 39 - Vasija en miniatura procedente de la Plaza III.

morfología inca. Es verdad que en el estilo Ychsma siempre ha habido un pequeño componente de cerámica de pasta gris que sale del horno con una superficie negra bruñida, pero este componente es muy reducido es decir un $3 \%$ no más en el Ychsma Medio (13). En esa época las formas eran muy sencillas e imitaban las formas de pasta naranja, o sea jarras con cuellos evertidos o abombados, a veces con una animal modelado sobre el cuerpo superior (Fig. 40). En el Ychsma Tardío empezaron a fabricar cuencos carenados con y sin reborde pero parece que no son muy frecuentes. Fueron cocidas en una atmósfera reductora para dar la superficie negra y a diferencia de las vasijas de pasta naranja fueron bruñidas (Paredes \& Ramos, 1994: fig. 43f).

(13) Bandelier excavó 227 vasijas del cementerio delante del Templo Pintado. Seis de estos son de pasta gris, tipo negro pulido, es decir un 2,6\%. Ya hemos mencionado la cerámica del sector Las Palmas. De los 3715 tiestos recuperados en Las Palmas solo 61 (1,64 \%) eran del tipo negro pulido o pasta gris (Paredes \& Ramos, 1989: 329, Cuadro 1). 


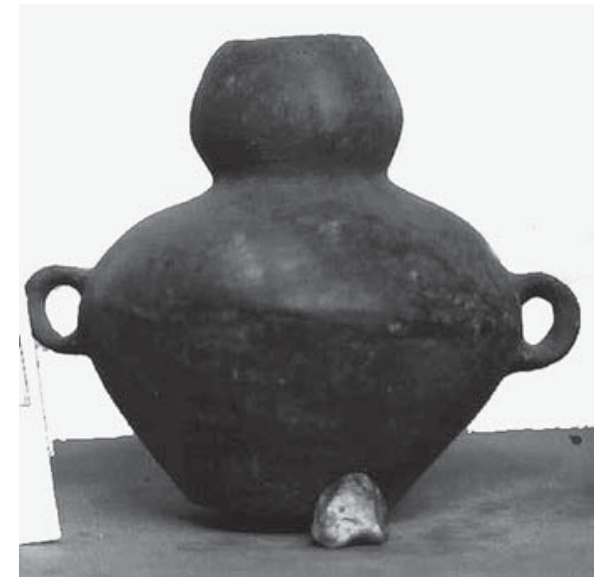

Fig. 40 - Vasija negra del Ychsma Medio con cuello abombado, excavada por Adolphe Bandelier.

Como ya se ha explicado, los saqueadores de las pirámides han revuelto todo de modo que es difícil encontrar contextos seguros. Los fechados radiocarbónicos (Michczynski et al., 2003) sitúan la construcción de la pirámide IIIB hacia fines del siglo catorce y la de la pirámide IIIA un poco más tarde. La cerámica que hemos descrito arriba, denominándola Ychsma Tardío proviene mayormente de la pirámide IIIB. Pero no por esto se debe pensar que no hay fragmentos de Ychsma Medio en dicha pirámide porque hemos encontrado bastante. El frasquito de la figura 7 es un buen ejemplo. Lo que sí queremos decir es que la evolución del estilo Ychsma fue un proceso lento, y los rasgos que lo definen no cambiaron repentinamente. Es lógico que muchas formas y métodos de decoración del Ychsma Medio hayan continuado hasta las últimas décadas del siglo catorce y principios del siglo quince. Lo mismo pasó después de la conquista Inca o sea que continuaron fabricando la misma cerámica de antes y poco a poco adoptaron nuevas formas, motivos decorativos, colores etc. Al mismo tiempo, como se ha afirmado arriba, queremos saber si hay una diferencia entre lo que fabricaban a fines del Intermedio Tardío y lo que fabricaban después de la llegada de los incas a la costa central. Abajo en el cuadro III se presenta una lista de elementos de la cerámica que fueron influenciados por los incas o que ellos mismos introdujeron. Según lo expuesto arriba, pudimos averiguar estos cambios al analizar la cerámica de algunas capas más bajas de la pirámide III con contextos seguros, la cual cotejamos con la cerámica de las excavaciones en la Plaza IV del Templo del Mono y con la que proviene de los hallazgos recientes en Armatambo y otros lugares.

En cuanto a las pastas, con la llegada de alfareros de otras regiones, la cerámica de Pachacamac tomó muchas senderos diferentes. Empezaron a fabricar vasijas de estilo Inca, las cuales solemos llamar estilo Inca Provincial; de estilo Chimú —el cual llamamos Inca Chimú o Pachacamac Inca Black Ware y uno híbrido de rasgos Inca, Chimu e Ychsma- (Fig. 41). Se notan unas pastas mucho más finas que no se veían desde el Intermedio Temprano. También se notan las inclusiones de piedrecitas negras, marrón y rojas que no había antes. 


\section{Cuadro 3 - Aportes de los incas a la cerámica Ychsma.}

1. Nuevos tipos de inclusiones en la pasta naranja

2. Tendencia a labios aplanados y/o fuertemente biselados al exterior

3. Bandas blancas verticales más ordenadas y bastante anchas sobre un engobe rojo

4. Engobe guinda, casi púrpura

5. Aumento de la cerámica negra. Decoración incisa de diseños geométricos pintados después de la cocción

6. Serpientes pareadas modeladas horizontales sobre el cuerpo superior y/o el cuello de la vasija

7. Batracios (¿sapos?) modelados de forma que parecen agarrados al borde mismo del cuello

8. Otros apéndices zoomorfos que siempre están colocados en el borde mismo de la vasija

Ya hemos llamado la atención sobre los labios biselados y aplanados. Creemos que algunos se remontan a la última fase del Intermedio Tardío, pero la mayoría se deben a la influencia Inca. Lo más notable son las vasijas con labio en forma de "media flecha" y los labios planos de los cuellos evertidos que tienen un asa que une el labio con la parte superior del cuerpo (Fig. 19). En el Intermedio Tardío, según vemos en el Templo del Mono, las asas unían la porción media del cuello con el cuerpo (Fig. 32) ( $c f$. Díaz \& Vallejo, 2002: fig. 3 V2, fig. 4, V 6 y 9 y forma 15).

Pasando a la decoración, en el Ychsma Tardío se notan algunas vasijas con bandas blancas verticales, pero estas bandas son más estrechas y no alternan con el engobe rojo en una forma sistemática. Nos parece que después de la conquista Inca hicieron que las bandas blancas ocupasen una mayor superficie (Fig. 23). Bien se sabe que estas bandas cubren las tinajas de tipo "pepino" que son del Horizonte Tardío (Uhle, 1903: 63, fig. 66; Hyslop \& Mujica, 1992: fig. 19). A veces el engobe rojo llega a ser casi púrpura (Fig. 42) con un brillo metálico que puede estar relacionado con un pigmento de hematita especular (Feltham, 1983: 607) el cual también produce la cerámica negra según la cocción que se le da (Muelle, 1954: 189).

Es consabido que después de la conquista los incas trajeron a Pachacamac a alfareros Chimú para mejorar la producción de la cerámica en un lugar que querían que tuviera aún más renombre y fama. Entonces aumentó la manufactura de la cerámica de pasta gris para dar nuevas formas lo que resultó en el híbrido Inca-Chimú o Pachacamac Inca Black Ware (según Menzel, 1976: 122), que es del Horizonte Tardío y tampoco forma parte del estilo Ychsma porque la pasta es demasiado fina para ser considerada dentro de las normas del estilo Ychsma. En cuanto a la cerámica local de tipo negro pulido en el Horizonte Tardío, como ya hemos señalado, empezó la moda de decorar los cuencos carenados con incisiones que pintaron de negro, blanco, rojo y amarillo después 
de la cocción (Figs. 6 y 43). También modelaron aves o sapos que colocaron alrededor del borde del cuenco (Figs. 43a y b.)

En las pirámides A y B hay muchos labios planos biselados al exterior y hay mayor empleo del engobe rojo que a veces alcanza un matiz casi púrpura. Por otra parte en el Templo del Mono hay algunos cuencos carenados pero no hay serpientes, ni sapos,

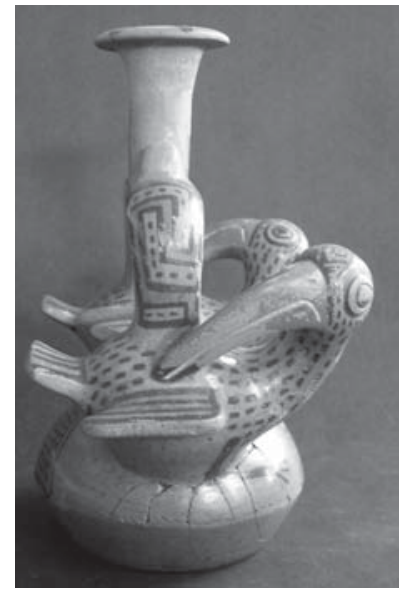

Fig. 41 - Botella Inca-Ychsma-Chimú procedente de la pirámide IIIA. La forma con asa estribo es Chimú. Los motivos son Ychsma y el labio plano con decoración de triángulos es Inca.

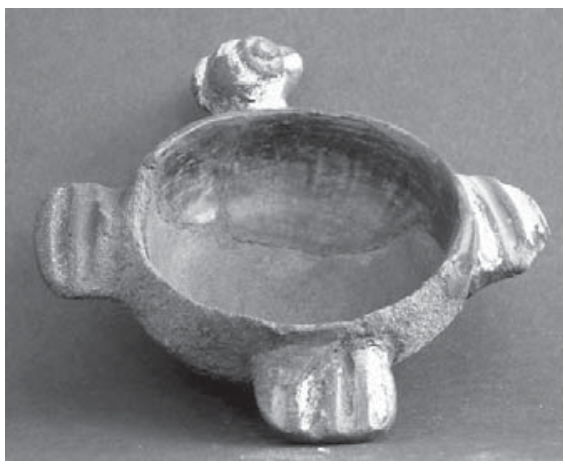

a)

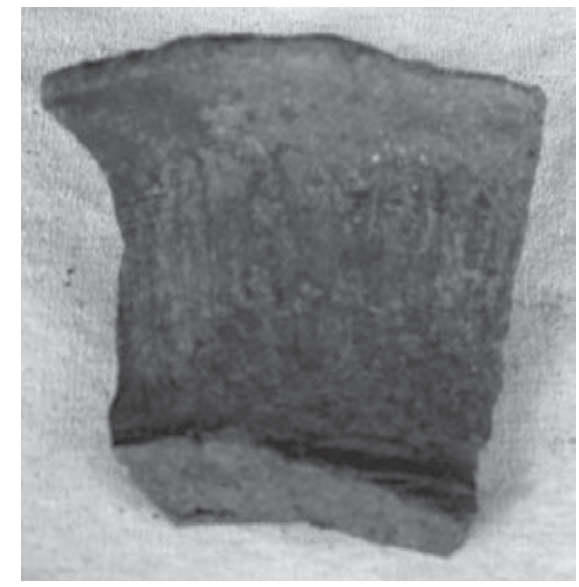

Fig. 42 - Tiesto con engobe rojo-púrpura de la Plaza II.

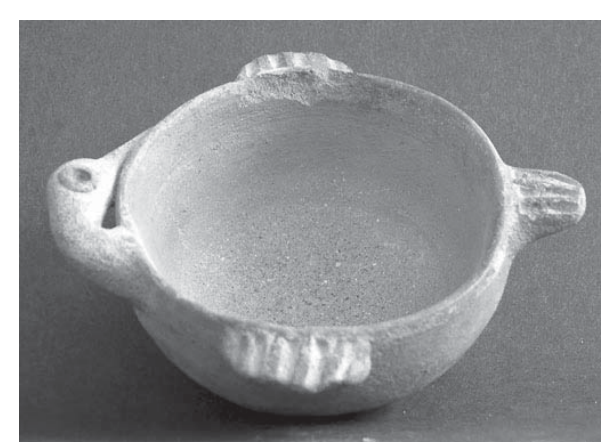

b)

Fig. 43 - a) Pequeño cuenco, tipo negro pulido, con ave modeladada en el borde y agarraderas pintadas después de la cocción. b) El mismo cuenco en pasta naranja. Los dos son del Incanato y provienen del valle del Lurín. 
que más son elementos serranos. En la sierra tanto el sapo como la serpiente están relacionados con el culto al agua. Se nota la disposición horizontal de la serpiente en las vasijas que encontró Bingham en Machu Picchu (Bingham, 1930: 151, figs. 104-105), y también aparece esculpida en los muros de piedra en Cuzco. Parece que los incas introdujeron estas formas a la cerámica Ychsma después de su llegada a la Costa Central. Reconocemos que la serpiente desempeñó un papel importante en la Costa Central en el Intermedio Temprano, como es evidente en los motivos del estilo Lima y algunos tapices de Ancón. El motivo de la serpiente continuó siendo modelado en las vasijas del Ychsma Medio pero es vertical con cabeza grande y no se encuentra con frecuencia (Fig. 44). Su forma es distinta a la de las serpientes de las vasijas del Horizonte Tardío.

Las diferencias que hemos señalado entre el Ychsma Medio, el Ychsma Tardío y el Ychsma del Incanato se destacan al cotejar la cerámica del Templo del Mono con la de las Pirámides IIIA y IIIB. En el Templo del Mono hay tiestos del Ychsma Medio, e incluso del Ychsma Inicial, que están asociados al estilo Rojo, Blanco y Negro Geométrico y con formas tempranas del punteado en zona. En este edificio no hay tiestos Inca sino de algunos entierros en el recinto de la entrada y solamente algunos del Ychsma Tardío, por ejemplo cuencos carenados pero sin sapos (Fig. 18a). Hay muy pocos diseños en negro sobre paneles blancos sobre un engobe rojo como se ven en las vasijas cara-gollete y los cuencos carenados. No hay serpientes, ni bordes con forma de media flecha tales como se encuentran en las piramides IIIA y IIIB. Ya se han publicado los fechados para estas dos pirámides, cuya construcción respectiva se puede fechar entre 1400 y 1430, es decir antes de la conquista Inca (Michczynski et al., 2003). Aunque hay dudas sobre la fecha de 1470 que sugirió Rowe (1946) para los comienzos del Incanato en la Costa Central, es improbable que los incas hayan llegado antes de 1420. De modo que estamos seguros que alguna parte de la cerámica Ychsma Tardío es

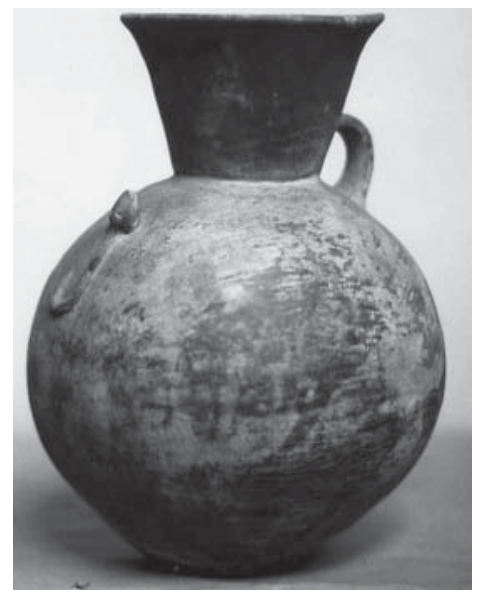

Fig. 44 - Jarra de Ychsma Medio, excavada por Adolphe Bandelier, tipo negro pulido, con serpiente vertical. 
anterior a esta conquista, como hemos tratado de demostrar arriba, separando los rasgos Inca del corpus del Ychsma Tardío.

Sin embargo, lo expuesto arriba son generalidades porque seguimos clasificando tanto las vasijas enteras como los tiestos entre varios tipos, los cuales daremos a conocer en un artículo de mayor envergadura. Además los nuevos descubrimientos que seguramente iremos haciendo van a agregar nuevas formas y diseños a nuestro corpus. Al difundir todos estos datos queremos hacer resaltar que nuestro corpus está compuesto mayormente de fragmentos que proceden de capas de ocupación, basurales o rellenos constructivos. Al mismo tiempo gran parte del material proviene también del relleno de huaquería que corresponde a los desechos de las tumbas saqueadas en un pasado más o menos lejano. En otros términos, tenemos pocos contextos de ajuar funerario, los cuales suelen ser empleados con fines de seriaciones cronológicas. Por estas razones hemos querido desarrollar metodologías alternativas para fechar la cerámica.

El siguiente método es uno que se ha elaborado en base a los fechados radiocarbónicos para los contextos y las asociaciones de tipos. Gracias a estos fechados y al estudio detallado del desarrollo arquitectónico del complejo pudimos determinar una serie de siete etapas sucesivas a partir de los fines del siglo catorce hasta la conquista española del siglo dieciséis (Michczynski et al., 2003). Cada capa estratigráfica (y el material que contiene) puede ser relacionada con una o varias de estas etapas, exceptuándose las capas removidas por acción humana después de la Conquista. La seriación que se propone aquí abajo se hizo cotejando los contextos, fechados y asociaciones de los tipos y se presentará con todos sus detalles en otra ocasión. En el cuadro anexo (Cuadro 4) se ve una seriación de todos los tipos Ychsma de pasta naranja que se han encontrado en las pirámides IIIB y IIIA. Los tipos que llevan un número de 1 o de 1 a 2(14)en la columna con título "life" son más tempranas que los tipos que llevan un número 6 que son del Horizonte Tardío.

Es interesante notar que entre todos los tipos y sub-tipos que se definieron para el estilo Ychsma, un $18 \%$ se encuentra exclusivamente en el Período Intermedio Tardío y un $19 \%$ únicamente en el Horizonte Tardío. El resto del material, es decir más de un $60 \%$ existió ya en el Ychsma Tardío y siguió siendo producido bajo el Incanato. Esto indica que por más fuerte que fuese la influencia imperial, por ejemplo, al nivel de la cantidad de vasijas fabricadas, las formas locales siguieron siendo populares, hasta en sitios totalmente controlados y remodelados por los incas, según es el caso de Pachacamac. Aquí no haremos más que mencionar algunos elementos típicos del Ychsma Tardío y del Ychsma del Horizonte Tardío.

Por ejemplo encontramos que las tinajas con cuello ligeramente abultado y labio aplanado son muy típicas del Ychsma Tardío (tipo E I c, figura 35). También lo son los tinajones de paredes gruesas sin cuello (tipo E III). A nivel de la decoración, las formas (C I 1 i c ii y C I 1 i j ii), con cuellos evertidos cuyo interior lleva un punteado en zona,

(14) Las cifras de la segunda columna se refieren a la "vida" o life-span de un tipo. Para hacer la seriación se han empleado únicamente los tipos que provienen de contextos seguros. Los tipos que llevan una cifra 7 provienen de capas disturbadas y pueden caer o en el Intermedio Tardío o en el Horizonte Tardío o en los dos. 
Cuadro 4 - Seriación de los tipos dentro del estilo Ychsma.

\begin{tabular}{|c|c|c|c|c|c|c|c|c|c|}
\hline & Tipo & Life & Etapa 1 & Etapa 2 & Etapa & Etapa 4 & Etapa 5 & Etapa 6 & Etapa 7 (undet. \\
\hline & & & & & LIP & & & LH & \\
\hline 47 & C.I.2.i & 1 & & & & & & & \\
\hline 69 & C.II.2.i & I & & & & & & & \\
\hline 7 & B.II.1.b & 1 & XXX & & & & & & \\
\hline 17 & C.I.1.i.a.iii & 1 & XXX & & & & & & \\
\hline 28 & C.I.1.i.j.ii & 1 & XXX & & & & & & \\
\hline 42 & C.I.1.ii.i & 1 & XXX & & & & & & \\
\hline 51 & C.I.2.ii.d & 1 & XXX & & & & & & \\
\hline 53 & C.I.2.ii.f & 1 & XXX & & & & & & \\
\hline 61 & C.II.1.i.e & 1 & XXX & & & & & & \\
\hline 76 & C.III.1.a.ii & 1 & XXX & & & & & & \\
\hline 81 & C.III.2.c.i & 1 & XXX & & & & & & \\
\hline 85 & C.IV.b & 1 & XXX & & & & & & \\
\hline 87 & C.V.a.ii & 1 & XXX & & & & & & \\
\hline 90 & C.V.d & 1 & XXX & & & & & & \\
\hline 104 & E.I.a & 1 & XXX & & & & & & \\
\hline 30 & C.I.1.i.1 & $1-2$ & XXX & XXX & & & & & \\
\hline 46 & C.I.1.ii.1.ii & $1-2$ & XXX & XXX & & & & & \\
\hline 59 & C.II.1.i.c & $1-2$ & XXX & XXX & & & & & \\
\hline 106 & E.I.c & $1-2$ & XXX & XXX & & & & & \\
\hline 109 & E.III & $1-2$ & XXX & XXX & & & & & \\
\hline 20 & C.I.1.i.c.ii & $1-3$ & XXX & XXX & & & & & \\
\hline 83 & C.III.2.d & $1-3$ & XXX & XXX & & & & & \\
\hline 23 & C.I.1.i.f & $1-5$ & XXX & XXX & XXX & XXX & XXX & & \\
\hline 8 & B.II.1.c & $1-6$ & XXX & XXX & XXX & XXX & XXX & XXX & \\
\hline 12 & B.II.2.a & $1-6$ & XXX & XXX & XXX & XXX & XXX & XXX & \\
\hline 13 & B.II.2.b & $1-6$ & XXX & XXX & XXX & XXX & XXX & XXX & \\
\hline 15 & C.I.1.i.a.i & $1-6$ & XXX & XXX & XXX & XXX & XXX & XXX & \\
\hline 19 & C.I.1.i.c.i & $1-6$ & XXX & XXX & XXX & XXX & XXX & XXX & \\
\hline 21 & C.I.1.i.d & $1-6$ & XXX & XXX & XXX & XXX & XXX & XXX & \\
\hline 22 & C.I.1.i.e & $1-6$ & XXX & XXX & XXX & XXX & XXX & XXX & \\
\hline 24 & C.I.1.i.g & $1-6$ & XXX & XXX & XXX & XXX & XXX & XXX & \\
\hline 29 & C.I.1.i.k & $1-6$ & XXX & XXX & $\mathrm{XXX}$ & XXX & XXX & XXX & \\
\hline 31 & C.I.1.i.m & $1-6$ & XXX & XXX & XXX & XXX & XXX & XXX & \\
\hline 32 & C.I.1.i.n & $1-6$ & XXX & XXX & XXX & XXX & XXX & XXX & \\
\hline 34 & C.I.1.ii.a & $1-6$ & XXX & XXX & XXX & XXX & XXX & XXX & \\
\hline 41 & C.I.1.ii.h & $1-6$ & XXX & XXX & XXX & XXX & XXX & XXX & \\
\hline 43 & C.I.1.ii.j & $1-6$ & XXX & XXX & XXX & XXX & XXX & XXX & \\
\hline 48 & C.I.2.ii.a & $1-6$ & XXX & XXX & XXX & XXX & XXX & XXX & \\
\hline 49 & C.I.2.ii.b & $1-6$ & XXX & XXX & XXX & XXX & XXX & XXX & \\
\hline 52 & C.I.2.ii.e & $1-6$ & XXX & XXX & $\mathrm{XXX}$ & XXX & $\mathrm{XXX}$ & XXX & \\
\hline 60 & C.II.1.i.d & $1-6$ & XXX & XXX & XXX & XXX & XXX & XXX & \\
\hline 67 & C.II.1.ii.a.i & $1-6$ & XXX & XXX & $\mathrm{XXX}$ & $\mathrm{XXX}$ & $\mathrm{XXX}$ & $\mathrm{XXX}$ & \\
\hline 74 & C.II.2.ii.e & $1-6$ & XXX & XXX & $\mathrm{XXX}$ & XXX & XXX & XXX & \\
\hline 77 & C.III.1.b & $1-6$ & XXX & XXX & XXX & XXX & XXX & XXX & \\
\hline 86 & C.V.a.i & $1-6$ & XXX & $\mathrm{XXX}$ & XXX & $\mathrm{XXX}$ & XXX & XXX & \\
\hline 88 & C.V.b & $1-6$ & XXX & XXX & XXX & XXX & XXX & XXX & \\
\hline 105 & E.I.b & $1-6$ & XXX & XXX & XXX & XXX & XXX & XXX & \\
\hline $14 \mathrm{a}$ & B.II.2.c.i & 2 & & XXX & & & & & \\
\hline 64 & C.II.1.i.h & 2 & & XXX & & & & & \\
\hline $14 b$ & B.II.2.c.ii & $2-6$ & & XXX & $\mathrm{XXX}$ & XXX & XXX & XXX & \\
\hline 16 & C.I.1.i.a.ii & $2-6$ & & XXX & XXX & XXX & XXX & XXX & \\
\hline 27 & C.I.1.i.j.i & $2-6$ & & XXX & XXX & XXX & XXX & XXX & \\
\hline 40 & C.I.1.ii.g & $2-6$ & & XXX & $\mathrm{XXX}$ & XXX & XXX & XXX & \\
\hline 62 & C.II.1.i.f & $2-6$ & & XXX & XXX & XXX & XXX & XXX & \\
\hline 75 & C.III.1.a.i & $2-6$ & & XXX & XXX & XXX & XXX & XXX & \\
\hline 84 & C.IV.a & $2-6$ & & XXX & XXX & XXX & XXX & XXX & \\
\hline 89 & C.V.c & $2-6$ & & XXX & $\mathrm{XXX}$ & XXX & $\mathrm{XXX}$ & XXX & \\
\hline
\end{tabular}




\begin{tabular}{|c|c|c|c|c|c|c|c|c|}
\hline 38 & C.I.1.ii.e & 3 & & XXX & & & & \\
\hline 63 & C.II.1.i.g & $3-6$ & & $\mathrm{XXX}$ & $\mathrm{XXX}$ & $\mathrm{XXX}$ & XXX & \\
\hline 73 & C.II.2.ii.d & $3-6$ & & XXX & XXX & XXX & XXX & \\
\hline 3 & B.I.a & $4-6$ & & & XXX & XXX & XXX & \\
\hline 6 & B.II.1.a & $4-6$ & & & XXX & XXX & XXX & \\
\hline $14 \mathrm{c}$ & B.II.2.c.iii & $4-6$ & & & XXX & XXX & XXX & \\
\hline 45 & C.I.1.ii.1.i & $4-6$ & & & XXX & XXX & XXX & \\
\hline 68 & C.II.1.ii.a.ii & $4-6$ & & & XXX & XXX & XXX & \\
\hline 97 & D.I.b & $4-6$ & & & XXX & XXX & XXX & \\
\hline 112 & F.III & $4-6$ & & & XXX & XXX & XXX & \\
\hline 57 & C.II.1.i.b.i & $5-6$ & & & & XXX & XXX & \\
\hline 107 & E.I.d & $5-6$ & & & & XXX & XXX & \\
\hline 108 & E.II & $5-6 *$ & & & & XXX & XXX & \\
\hline 1 & A.I & 6 & & & & & XXX & \\
\hline 2 & A.II & 6 & & & & & XXX & \\
\hline 9 & B.II.1.d & 6 & & & & & XXX & \\
\hline 11 & B.II.1.f & 6 & & & & & XXX & \\
\hline 18 & C.I.1.i.b & 6 & & & & & XXX & \\
\hline 25 & C.I.1.i.h & 6 & & & & & XXX & \\
\hline 26 & C.I.1.i.i & 6 & & & & & XXX & \\
\hline 33 & C.I.1.i.o & 6 & & & & & XXX & \\
\hline 36 & C.I.1.ii.c & 6 & & & & & XXX & \\
\hline 37 & C.I.1.ii.d & 6 & & & & & XXX & \\
\hline 54 & C.I.2.ii.g & 6 & & & & & XXX & \\
\hline 56 & C.II.1.i.a & 6 & & & & & XXX & \\
\hline 72 & C.II.2.ii.c & 6 & & & & & XXX & \\
\hline 92 & C.VI.1 & 6 & & & & & XXX & \\
\hline 93 & C.VI. 2 & 6 & & & & & XXX & \\
\hline 94 & C.VI.3 & 6 & & & & & XXX & \\
\hline 98 & D.I.c & 6 & & & & & XXX & \\
\hline 99 & D.I.d & 6 & & & & & XXX & \\
\hline 103 & D.II.b & 6 & & & & & XXX & \\
\hline 4 & B.I.b. & 7 & & & & & & \\
\hline 5 & B.I.c & 7 & & & & & & \\
\hline 10 & B.II.1.e & 7 & & & & & & \\
\hline 35 & C.I.1.ii.b & 7 & & & & & & \\
\hline 39 & C.I.1.ii.f & 7 & & & & & & \\
\hline 44 & C.I.1.ii.k & 7 & & & & & & \\
\hline 50 & C.I.2.ii.c & 7 & & & & & & \\
\hline 55 & C.I.2.ii.h & 7 & & & & & & \\
\hline 58 & C.II.1.i.b.ii & 7 & & & & & & \\
\hline 65 & C.II.1.i.i & 7 & & & & & & \\
\hline 66 & C.II.1.i.j & 7 & & & & & & \\
\hline 70 & C.II.2.ii.a & 7 & & & & & & \\
\hline 71 & C.II.2.ii.b & 7 & & & & & & \\
\hline 78 & C.III.2.a & 7 & & & & & & \\
\hline 79 & C.III.2.b.i & 7 & & & & & & \\
\hline 80 & C.III.2.b.ii & 7 & & & & & & \\
\hline 82 & C.III.2.c.ii & 7 & & & & & & \\
\hline 91 & C.V.e & 7 & & & & & & \\
\hline 95 & C.VII & 7 & & & & & & \\
\hline 96 & D.I.a & 7 & & & & & & \\
\hline 100 & D.I.e & 7 & & & & & & \\
\hline 101 & D.I.f & 7 & & & & & & \\
\hline 102 & D.II.a & 7 & & & & & & \\
\hline 111 & F.II & 7 & & & & & & \\
\hline \multirow[t]{2}{*}{110} & F.I & 7 & & & & & & \\
\hline & Type & Life & Step 1 S. 2 & S. 3 & Step 4 & Step 5 & Step 6 & Step 7 (undet.) \\
\hline
\end{tabular}


tienen su origen en el Intermedio Tardío y dejaron de ser elaboradas en el Incanato. Las vasijas con cara-gollete (C I 1 ii g) aparecen en nuestras excavaciones a partir de 1400 y siguen siendo producidas durante el Incanato.

Los elementos Ychsma característicos del Horizonte Tardío ya han sido descritos pero hay que subrayar que la seriación comprueba que la forma cuzqueña del plato (A I) fue introducida por los mismos incas; que hubo imitaciones (A II) pero que no existió en el Ychsma Tardio del Intermedio Tardío. Las botellas con cuello estribo (D II b) son también diagnósticas del Incanato, así como los cuencos abiertos de un negro pulido y de labio muy plano. Ya hemos explicado que la pasta gris con un acabado negro pulido no es un rasgo exclusivo del Horizonte Tardío pues ya existía en el Ychsma Tardío pero su proporción aumentó bastante durante el Horizonte Tardío con nuevas pastas, formas, y decoración. Al mismo tiempo no se debe confundir estos tipos nuevos que son más de la tradición Ychsma con el Negro Pulido que tiene cierto brillo y unos reflejos metálicos que forma parte del estilo Inca Chimú o Pachacamac Inca Black Ware.

Entonces resumimos abajo los puntos más importantes de nuestras investigaciones:

1. El Ychsma Tardío es una continuación del estiloYchsma Medio y parece haber evolucionado hacia los fines del siglo catorce perdurando durante todo el siglo quince hasta la conquista española.

2. Los rasgos salientes son un mayor uso del engobe rojo como fondo para diseños en blanco y negro. Los motivos son geométricos y zoomorfos, consistiendo en rectángulos o triángulos con puntitas dentro o peces y aves estilizadas. La forma de la cara-gollete se hizo popular junto con una preferencia para las asas horizontales en las vasijas sencillas. Cuando hubo asas verticales estas unían el labio con la parte superior del cuerpo, si bien hay excepciones en los frascos y vasijas cara-gollete.

3. Decayó la técnica del punteado en zona que se limitó a dos líneas en zigzag, colocadas en el interior del cuello, con una sola fila de puntitas dentro. Al mismo tiempo se hizo popular la decoración por medio de una punta de caña, formándose dos filas alrededor de la parte superior de la vasija.

4. Las formas también evolucionaron. Las formas nuevas más destacadas son los cuencos carenados con o sin reborde.

5. La conquista inca produjo un aumento en la cantidad de cerámica fabricada a la vez que introdujo nuevas técnicas, formas, y decoraciones para resultar en una cerámica Inca Ychsma de la que hemos podido dar unos pocos detalles aquí.

Nota sobre las formas. Solemos repartir las formas en seis clases:

a) Los platos son recipientes muy abiertos, casi planos, con un diámetro mucho más grande que su altura, la que no suele sobrepasar los $4 \mathrm{~cm}$.

b) Los cuencos son recipientes que no llevan cuello. Los cuencos abiertos tienen una boca más grande o igual al diámetro máximo de la vasija; b) los cerrados tienen una boca más reducida que el diámetro máximo. Los dos pueden llevar un pequeño reborde. 
c) Las jarras son recipientes con un cuello que puede tomar varias formas. Hay que notar que no hacemos diferencia entre un cántaro y una olla, como hacen muchos, en el sentido de que una olla es para cocinar y un cántaro para contener líquidos. Como el estado actual de nuestros conocimientos no nos permite conocer la función de estas vasijas, es aventurado hacer esta distinción, sobre todo cuando se trata de fragmentos.

d) Las botellas y frascos son recipientes con un cuello angosto. En las botellas la boca del cuello no supera los $4 \mathrm{~cm}$ de diámetro. El frasco posee un diámetro de más de $4 \mathrm{~cm}$ y menos de $8 \mathrm{~cm}$. Todos los cuellos altos que tienen un diámetro mayor de $8 \mathrm{~cm}$ se clasifican en (c) es decir jarras, si bien muchos quieren llamarlos cántaros. Otros incluyen vasijas con un cuello alto que tiene un diámetro de $9 \mathrm{~cm}$ o más cuando definen una botella. Estos los llamamamos jarras con cuello alto.

e) Las tinajas y tinajones son recipientes muy grandes. Se supone que son para almacenar alimentos, sean estos líquidos o sólidos. Las tinajas son más grandes que las jarras con un borde de más de $30 \mathrm{~cm}$ de diámetro y con paredes mucho mas gruesas que las jarras, alcanzando un grosor de $1 \mathrm{~cm}$. Los tinajones tienen paredes de $2 \mathrm{~cm}$ de grueso y una altura de más de un metro.

f) Las vasijas en miniatura son recipientes para ofrendas y no miden más de $10 \mathrm{~cm}$ de alto. Uno puede compararlas con las prendas en miniatura que también se daban como ofrenda. Estas vasijas pueden ser cuencos o jarras.

\section{Agradecimientos}

Al British Academy de Londres por haber patrocinado el viaje de la primera autora al Perú en 2003. Al INC por haber otorgado los permisos respectivos. Al Centro de Investigaciones Arqueológicas de la Universiad Libre de Bruselas, el Fondo Nacional Belga de la Investigación Científica, el Committee for Research and exploration de la National Geographic Society por haber contribuido en la financiación del Proyecto Ychsma en Pachacamac así como a todos los integrantes del equipo de campo. Agradecemos también a todos los colegas que nos han ayudado en discusiones y comentarios.

\section{Referencias citadas}

BAZÁN DEL CAMPO, F., 1990 - Arqueología y Etnohistoria de los Períodos Prehispánicos Tardíos de la Costa Central del Perú. Tesis de Licenciatura, Universidad Nacional Mayor de San Marcos; Lima.

BAZÁN DEL CAMPO, F., 1992 - Arqueología de Lima: Evaluación del término Huancho. Los estilos de cerámica de Lima a fines del horizonte Medio, 43p.; Lima: CREARTES.

BINGHAM, H., 1930 - Types of Machu Picchu Pottery. American Anthropologist, new series, vol. 17, n' 2: 165-181; Boston.

BONAVIA, D., 1959 - Cerámica de Puerto Viejo (Chilca). In: Actas del II congreso Nacional de Historia del Perú (época prehispánica): 137-168; Lima: Centro de estudios históricos y militares del Perú.

BUENO MENDOZA, A., 1978 - El Señorío de Ichimay. Espacio, vol. 1, nº 2: 64-71; Lima. 
BUENO MENDOZA, A., 1982 - El antiguo valle de Pachacamac. Boletín de Lima, $\mathbf{n}^{\circ} 24$ (4): 10-29; Lima.

CORNEJOGUERRERO, M.A., 1999-AnArchaeologicalAnalysis of an InkaProvince:Pachacamac and the Ischma Nation of the Central Coast of Peru. Ph.D. Thesis. Department of Anthropology and Archaeology. The Australian National University; Canberra.

CORNEJO GUERRERO, M. A., 2000 - La nación ischma y la provincia inka de Pachacamac. Arqueológicas, tomo 24: 149-173; Lima: Instituto Nacional de Cultura.

DÍAZ ARRIOLA, L. \& VALLEJO BERRÍOS, F., 2002 - Identificación de Contextos Ichma en Armatambo. Arqueología y Sociedad, no 14: 47-75; Lima: Museo de Arqueología y Antropología, Universidad Nacional Mayor de San Marcos.

DÍAZ ARRIOLA, L. \& VALLEJO BERRÍOS, F., 2004 - Armatambo y el dominio incaico en el valle de Lima. Boletín de Arqueología PUCP, no 6: 336-368. Lima: PUC.

EECKHOUT, P., 1999-Pachacamac durantl'Intermédiaire Récent. Étude d'un site monumental préhispanique de la Côte Centrale du Pérou, 504p.; Oxford: BAR International Series.

FELTHAM, J., 1983 - The Lurín valley, Peru: A. D. 1000- 1532. Un published Ph. D. Tesis; London University, Ms.

FELTHAM, J., 1984 - The Lurin valley proyect. Some result for the late Intermediate and Late Horizon (A. Kendall, ed.): 45-73; Oxford: BAR Inernational Series 210.

FRANCO JORDÁN, R., 1998 - La pirámide con rampa $N^{\circ} 2$ de Pachacamac. Excavaciones y nuevas interpretaciones, $105 \mathrm{p}$.; Trujillo.

HYSLOP, J. \& MUJICA B., E., 1992 -Investigaciones de A. F. Bandelier en Armatambo (Surco) en 1892. Gaceta Arqueológica Andina, nº 22: 63-86; Lima: Instituto Andino de Estudios Arqueológicos.

IRIARTE BRENNER, F., 1960 - Algunas apreciaciones sobre los Huanchos. In: Antiguo Perú Espacio y Tiempo, Trabajos presentados a la Semana de Arqueología Peruana (9-14 de noviembre de 1959) (R. Matos Mendieta, ed.): 259-263; Lima: Editorial Juan Mejía Baca.

ISLA C., J., 1995 - Materiales recuperados por Max Uhle (1906-1907) en la Isla de San Lorenzo, Costa Central del Perú. Gaceta Arqueológica Andina, $\mathbf{n}^{0}$ 24: 73-91; Lima: Instituto Andino de Estudios Arqueológicos.

KROEBER, A. L. \& STRONG, W. D., 1924 - The Uhle Pottery Collections from Chincha. University of California Publications in American Archaeology and Ethnology, V. 21: 1-54; Berkeley.

MENZEL, D., 1976 - Pottery Style and Society in Ancient Peru: Art as a Mirror of History. Berkeley: University of California Press.

MENZEL, D., 1977 - The Archaeology of Ancient Peru and the Work of Max Uhle; Berkeley: University of California. R. H. Lowie Museum of Anthropology.

MICHCZYNSKI, A., EECKHOUT, P. \& PADZUR, A., 2003 - 14C Absolute Chronology of Pyramid III and the Dynastic Model at Pachacamac, Peru. Radiocarbon, 45, 1: $59-73$.

MUELLE, J. C., 1954 - Acerca del Estilo Chimú Medio. Revista del Museo Nacional, Tomo XXIII: 182-197: Lima.

PAREDES BOTONI, P. \& RAMOS GIRALDO, J., 1994 - Excavaciones Arqueológicas en el Sector Las Palmas, Pachacamac. Boletín de Lima, XVI, no 91-96: 313-349; Lima.

RAMÓN JOFFRÉ, G., 1999-Producción Alfarera en Santo Domingo de los Olleros (HuarochiríLima). Bulletin de l'Institut Français d'Études Andines, 28(2): 215-248.

ROSTWOROWSKIDE DIEZ CANSECO, M., 1972 - Breve ensayo sobre el señorío de Ychma. Arqueología PUC, $\mathbf{n}^{\circ}$ 13: publicado de nuevo en 1977. In: Etnía y Sociedad: Costa Peruana Prehispánica: 197-210; Lima: Instituto de Estudios Peruanos.

ROSTWOROWSKI DE DIEZ CANSECO, M., 1978 - Señoríos Indígenas de Lima y Canta, 280p.; Lima: Instituto de Estudios Peruanos, 
ROWE, J., 1946 - Inca culture at the time of the Spanish Conquest. In: Handbook of South Amrican Indians, Vol. II (J. H. Steward, ed.): 183-330; Washington D.C.: Bureau of American Ethnology, Bulletin 143.

SILVA S., J. E., 1992 - Ocupaciones postformativas en el valle del Rímac: Huachipa-Jicamarca. Pachacamac, Revista del Museo de la Nación, vol. 1, no 1: 75-100; Lima: Museo de la Nación.

STRONG, W. D., 1925 - The Uhle Collections from Ancón. In: University of California Publications in American Archaeology and Ethnology, vol 21: 135-190: Berkeley.

STRONG, W.\& CORBETT, M., 1943 - A Ceramic Sequence at Pachacamac. In: Archeological Studies in Peru, 1941-1942 (William D. Strong, Gordon R. Willey \& John M. Corbett, eds.): 27-122; New York: Colombia University Press. Columbia University Studies in Archeology and Ethnology, vol. I.

UHLE, M., 1903 - Pachacamac: Report of the William Pepper, M.D., LL.D. Peruvian Expedition of 1896; Philadelphia: University of Pennsylvania, Department of Archaeology.

VILLAR CÓRDOVA, P., 1935 - Las culturas prehispánicas del Departamento de Lima.

WILlEY, G. R., 1943 - A Supplement to the Pottery Sequence at Ancón. In: Columbia University Studies in Archaeology and Ethnology (W. D. Strong et al., eds.): 201-212; New York: Columbia University Press. 